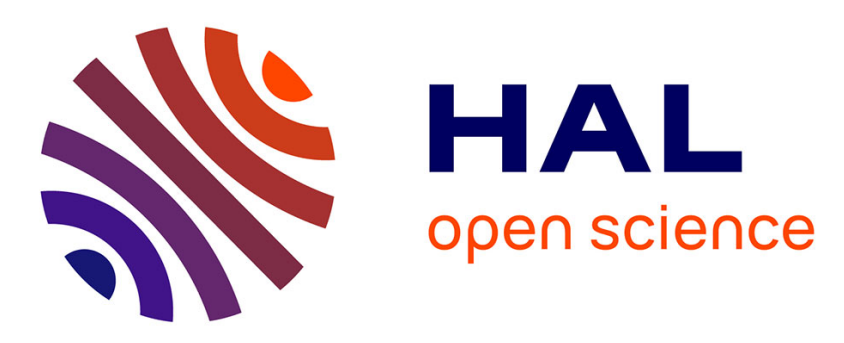

\title{
Mental fatigue induced by prolonged motor imagery increases perception of effort and the activity of motor areas
}

Thomas Jacquet, Romuald Lepers, Bénédicte Poulin-Charronnat, Patrick Bard, Philippe Pfister, Benjamin Pageaux

\section{To cite this version:}

Thomas Jacquet, Romuald Lepers, Bénédicte Poulin-Charronnat, Patrick Bard, Philippe Pfister, et al. Mental fatigue induced by prolonged motor imagery increases perception of effort and the activity of motor areas. Neuropsychologia, 2021, 150, pp.107701. 10.1016/j.neuropsychologia.2020.107701 . hal-03094633

\section{HAL Id: hal-03094633 \\ https://hal.science/hal-03094633}

Submitted on 18 Jun 2021

HAL is a multi-disciplinary open access archive for the deposit and dissemination of scientific research documents, whether they are published or not. The documents may come from teaching and research institutions in France or abroad, or from public or private research centers.
L'archive ouverte pluridisciplinaire HAL, est destinée au dépôt et à la diffusion de documents scientifiques de niveau recherche, publiés ou non, émanant des établissements d'enseignement et de recherche français ou étrangers, des laboratoires publics ou privés. 


\section{Mental fatigue induced by prolonged motor imagery increases perception of effort and the activity of motor areas}

Thomas Jacquet $^{1}$, Romuald Lepers ${ }^{2}$, Bénédicte Poulin-Charronnat ${ }^{1}$, Patrick Bard ${ }^{1}$, Philippe Pfister $^{1}$, and Benjamin Pageaux ${ }^{2,3,4}$

${ }^{1}$ LEAD, CNRS UMR5022, Université Bourgogne Franche-Comté, 21000 Dijon, France

${ }^{2}$ INSERM UMR1093-CAPS, Université Bourgogne Franche-Comté, UFR des Sciences du Sport, F-21000 Dijon, France

${ }^{3}$ Ecole de kinésiologie et des sciences de l'activité physique (EKSAP), Faculté de médecine, Université de Montréal, Montréal, Québec, Canada.

${ }^{4}$ Centre de Recherche de l'Institut Universitaire de Gériatrie de Montréal (CRIUGM), Montréal, Québec, Canada

\section{Corresponding author:}

Thomas Jacquet, LEAD - CNRS UMR5022, Université Bourgogne Franche-Comté

I3M, 64 Rue de Sully 21000 Dijon, France

Tel: +33 380395772

Fax: +33380395767

E-mail: thomas.jacquet@u-bourgogne.fr

\section{Funding statement}

Nothings to declare

\section{Funding statement}

The Authors have no conflict of interest to disclose in respect to this manuscrit 


\begin{abstract}
Recent literature suggests that when prolonged, motor imagery (MI) induces mental fatigue and negatively impacts subsequent physical exercise. The aim of this study was to confirm this possibility with neurophysiological and self-reported measures. Thirteen participants performed 200 imagined isometric knee extension contractions (Prolonged MI condition) or watched a documentary (Control condition), and then performed 150 actual isometric knee extensions. Electroencephalography was continuously recorded to obtain motor-related cortical potential amplitude at $\mathrm{Cz}$ electrode (MRCP, index of motor area activity) for each imagined and actual contractions. Electromyography of the vastus lateralis muscle as well as the perceived effort required to perform prolonged MI, watch the documentary, and perform the actual contractions were measured. During prolonged MI, mental fatigue level, the effort required to imagine the contractions and MRCP amplitude increased over time. The increase in the effort required to imagine the contractions was significantly correlated with the MRCP amplitude. During the physical exercise, a significant condition $\times$ time interaction revealed a greater increase over time in perceived effort in the prolonged MI condition compared to the control condition, as well as a specific alteration in EMG RMS of the vastus lateralis muscle. These alterations observed in the presence of mental fatigue during actual contractions, combined with those observed during prolonged MI, suggest that prolonged MI may impair the motor command required to perform imagined or actual contractions. While the observed effect of mental fatigue on MRCP amplitude was clear during MI, future studies should tailor the physical exercise to minimize the exerciseinduced decrease in force production capacity and control for its confounding effects on MRCP amplitude in the presence of mental fatigue.
\end{abstract}

Keywords: Electroencephalography (EEG), Mental fatigue, Cognitive fatigue, Perception of effort, Perceived exertion, Motor related cortical potential (MRCP)

Acronyms: $\mathrm{EEG}=$ Electroencephalography; $\mathrm{EMG}=$ Electromyography; $\mathrm{MI}=$ Motor Imagery; MRCP = Motor Related Cortical Potential; MVC = Maximal Voluntary Contraction; NASA-TLX = National Aeronautics and Space Administration Task Load Index; RFD = Rate of Force Development; RMS = Root Mean Square; RPE = Rating of Perceived Effort; VAS = Visual Analogue Scale 


\section{INTRODUCTION}

Mental fatigue is defined as a psychobiological state caused by prolonged periods of demanding cognitive activity and characterized by subjective feelings of "tiredness" and "lack of energy" (Boksem and Tops, 2008). Since the pioneer study of Marcora et al. (2009) demonstrating an impairment in cycling endurance performance following prolonged engagement in a demanding cognitive task, numerous studies confirmed the negative impact of mental fatigue on physical performances (for reviews see: Pageaux and Lepers, 2018; Brown et al., 2020). Mental fatigue impairs sport-related decision making (Head et al., 2017; e.g., Smith et al., 2016b), technical skills (Le Mansec et al., 2018; e.g., Smith et al., 2016a), motor control (e.g., Duncan et al., 2015; Rozand et al., 2015) and endurance (MacMahon et al., 2014; e.g., Pageaux et al., 2013) performances. Decrease in physical performances is generally associated with alteration in cardiorespiratory or metabolic responses and/or an inability of the brain to maximally recruit the working muscles (Taylor et al., 2016). However, mental fatigue does not induce such alterations (Marcora et al., 2009; Pageaux et al., 2013). The only variable consistently associated with the decrease in physical performance was a greater perception of effort in the presence of mental fatigue (Brown et al., 2020; Le Mansec et al., 2018; Pageaux and Lepers, 2018, 2016).

Mental fatigue is traditionally induced by prolonged engagement in cognitive tasks involving the response inhibition process, such as the AX-CPT (Marcora et al., 2009; Pageaux et al., 2013; Smith et al., 2015) or the Stroop task (Rozand et al., 2015; Smith et al., 2016a). Interestingly, recent studies using motor imagery demonstrated that such cognitive exertion may also induce mental fatigue (Graham et al., 2014; Rozand et al., 2016, 2014). Motor imagery is defined as the internal simulation of movement without corresponding motor output (Decety, 1996a). Briefly, two main categories of motor imagery exist: visual motor imagery and kinesthetic motor imagery. Visual motor imagery consists of imagining seeing yourself performing the task and activates predominantly the occipital network (Chholak et al., 2019; Guillot et al., 2009). Kinesthetic motor imagery consists of imagining the sensations produced by the actual task and activates to a lesser extent similar brain areas than those activated during actual movements such as the premotor cortex, the parietal cortex and the cerebellum (e.g., Batula et al., 2017; Decety, 1996b; Ruffino et al., 2017; Solodkin et al., 2004; Stinear et al., 2006). 
In a meta-analysis, Schuster et al. (2011) reported that $\sim 17$ minutes of motor imagery is optimal to observe positive effects on physical performance (e.g., Yue and Cole, 1992; Grosprêtre et al., 2018; Ranganathan et al., 2004), thus reinforcing the potential for its use in rehabilitation programs (e.g., Jackson et al., 2001; Lebon et al., 2012; Cho et al., 2013; Kumar, 2016). However, the positive effects of motor imagery seem to disappear when motor imagery is performed longer than the optimal duration proposed by Schuster et al. (2011). Indeed, Rozand et al. (2016) recently demonstrated that 100 imagined contractions (i.e., $\sim 30 \mathrm{~min}$ ) induced mental fatigue and increased movement duration during a pointing task. The involvement of the sustained attention and the inhibitory processes during a motor imagery task (Bart et al., 2020; O'Shea and Moran, 2017), as in cognitive tasks classically used to induce mental fatigue (e.g., AX-CPT, Stroop), could be one of the underlying mechanisms explaining the occurrence of mental fatigue. As mental fatigue could counteract the positive effects of motor imagery on subsequent performance, and therefore impair rehabilitation programs, it is important to investigate the occurrence of mental fatigue induced by prolonged motor imagery.

While the underlying mechanisms causing the decrease in physical performance in the presence of mental fatigue remain unclear, analysis of brain oscillations via electroencephalography (EEG) has been an efficient tool to identify mental fatigue-induced cerebral alterations during the completion of cognitive tasks (for review: Craig et al., 2012; Tran et al., 2020). Analyses of brain oscillations reveal a consistent increase in the theta power (e.g., Barwick et al., 2012) and alpha power (e.g., Shou and Ding, 2013) in the presence of mental fatigue. These changes were not only reported after cognitive tasks requiring predominantly the response inhibition process but also after cognitive tasks requiring concentration and attention (Lal and Craig, 2002; van der Linden et al., 2003). As these studies did not use prolonged motor imagery to induce mental fatigue, it remains unknown whether these alterations are transferable to mental fatigue induced by prolonged motor imagery.

When measuring cerebral activity with EEG, it is possible to monitor for each contraction (actual or imagined) a specific event-related potential called motor-related cortical potential (MRCP; e.g., Jankelowitz and Colebatch, 2002; do Nascimento et al., 2006). This potential was discovered during hand movements by Bates (1951) and recorded from the scalp overlying motor and premotor areas. MRCP amplitude is directly linked to the intensity of muscle contraction and has been extensively used in the literature as an index of the motor command (de Morree et al., 
2014, 2012; Siemionow et al., 2000). In the presence of decreased maximal force production capacity, also known as muscle fatigue (Gandevia, 2001), previous studies observed an increased MRCP while the level of muscle force during each contraction remained constant (de Morree et al., 2014, 2012). As previous studies observed i) alterations in electromyographic signal of the working muscles during submaximal physical exercise following engagement in demanding cognitive tasks (Bray et al., 2008; Graham et al., 2014; Pageaux et al., 2015), and ii) longer duration of actual and imagined movement in the presence of mental fatigue (Rozand et al., 2015), it is plausible that mental fatigue may impact the regulation of the motor command and consequently alter MRCPs. This hypothesis is also supported by recent studies demonstrating an association between changes in MRCPs and perception of effort (de Morree et al., 2014, 2012). While an ongoing debate is still existing in the literature on the sensory signal generating perception of effort (peripheral vs central origin; e.g., Amann and Light, 2014; Broxterman et al., 2018; Marcora, 2009; Pageaux, 2016; Smirmaul, 2014; Steele and Fisher, 2018), this perception has been classically used as a marker of the motor command for decades (Kjær et al., 1999; McCloskey et al., 1974; Mitchell et al., 1989), and its consistent increase in the presence of mental fatigue (Brown et al., 2020; Pageaux and Lepers, 2018, 2016) reinforces the possible interaction between mental fatigue and the motor command.

In this context, the primary aim of the present study was to induce mental fatigue using prolonged motor imagery. EEG was recorded during four blocks of fifty imagined contractions, and subjective feelings of fatigue, as well as the effort required to imagine the contractions were reported. We hypothesized that prolonged motor imagery will successfully induce mental fatigue evidenced by an increase in feelings of fatigue as well as in the effort required to imagine the contractions, and an increase in both alpha and theta power. Due to the known negative impact of mental fatigue on subsequent physical performance (for review see: Pageaux and Lepers, 2018; Brown et al., 2020), the secondary aim of our study was to identify, during a subsequent physical exercise, neurophysiological alterations caused by mental fatigue. Finally, as i) mental fatigue is known to increase the perception of effort during physical exercises (Pageaux and Lepers, 2018), and ii), previous studies demonstrated an association between changes in perceived effort and changes in MRCP (de Morree et al., 2014, 2012) we expect that prolonged motor imagery will increase the amplitude of MRCPs during both imagined and actual contractions. 


\section{EXPERIMENTAL PROCEDURES}

\section{1. PARTICIPANTS}

Thirteen physically active right-handed adults ( 7 males and 6 females) volunteered in this study (mean $\pm \mathrm{SD}$; age: $25 \pm 4$ years, height: $182 \pm 5 \mathrm{~cm}$, weight: $77 \pm 11 \mathrm{~kg}$ ). This sample size was determined based on a previous study using a similar physical exercise with the knee extensors and investigating the relation between MRCP and physical fatigue in the presence and absence of caffeine (de Morree et al., 2014). All participants were involved in physical activity and declared to practice a physical activity at least one time per week. None of the participants had any known mental or somatic disorders or any injuries of the right leg during the last six months. All participants were given written instructions describing all procedures related to the study but were naive of its aims and hypotheses. The participants have never been informed prior to the experiment that motor imagery (MI) was used to generate mental fatigue. They were instructed that the aim of the study was to investigate the possible positive effects of motor imagery on a subsequent physical exercise. Each participant provided written informed consent. At the end of the last visit, participants were fully debriefed and asked not to discuss the real aims of the study with other participants. The study conformed to the standards set by the World Medical Association Declaration of Helsinki "Ethical Principles for Medical Research Involving Human Subjects" (2008). The experimental design of the study was approved by the regional ethics committee (CPP EST: approval no. A00064-49).

\section{2. PROCEDURE}

Participants visited the laboratory on three different occasions. Each participant completed all three visits over three weeks with a minimum of six days of recovery period between visits. All visits started between 8:30 a.m. and 10:00 a.m. All participants were given instructions to sleep for at least seven hours, refrain from the consumption of alcohol, and not to practice vigorous physical activity the day before each visit. Participants were also instructed not to consume caffeine and nicotine for at least three hours before testing and were asked to declare if they had taken any medication or had any acute illness, injury, or infection. At the beginning of each session, the participants attested that they had complied with all instructions. For all the sessions, participants sat on the same isometric ergometer chair (Multi-form, la Roque d'Anthéron, France). 
During the first visit, participants were familiarized with the laboratory and all the procedures. For all different questionnaires, oral and written instructions were provided during this familiarization (and recalled at the beginning of each visit). About the physical exercise, after a warm-up, participants performed 150 submaximal isometric knee extensions at $50 \%$ of their maximal voluntary contraction (MVC). If the physical exercise was too difficult during the familiarization session (i.e., excessive head movements and sweating) the target force was fixed at $45 \%$ of their MVC. On the contrary, if the physical exercise was too easy (i.e., low perceived effort at the end of the exercise and no muscular fatigue), the target force was fixed at $55 \%$ of their MVC. At the end of the familiarization, participants performed maximal imagined isometric contractions of the right knee extensors to get used to MI. After the familiarization, all participants reported that they successfully imagined the 50 contractions, felt associated sensations and reported a score of at least 5 on the Likert scale used to record the MI vividness (see section 2.4.4 Motor imagery vividness).

The second and third visits were randomized and counterbalanced. An overview of each visit is presented in Fig. 1. Each visit consisted of performing either prolonged MI or a control task (i.e., watching a documentary) for approximately $50 \mathrm{~min}$, followed by a physical exercise (150 isometric knee extensions). In each visit, participants reported their level of mental fatigue and performed MVC with their right knee extensors to assess force production capacity before and after (Post 1, before the subsequent physical exercise) the prolonged MI or documentary watching, as well as after the physical exercise (Post 2). Motivation to perform prolonged MI or watch the documentary, and perform the subsequent physical exercise was measured before completion of each task. Participants reported their perceived workload of the prolonged MI session, documentary watching and physical exercise after completion of each task. Electromyographical (EMG) and electroencephalographic (EEG) signals were continuously recorded during all tasks; and the participants reported their perceived effort to perform MI, watch the documentary or perform the physical exercise. 


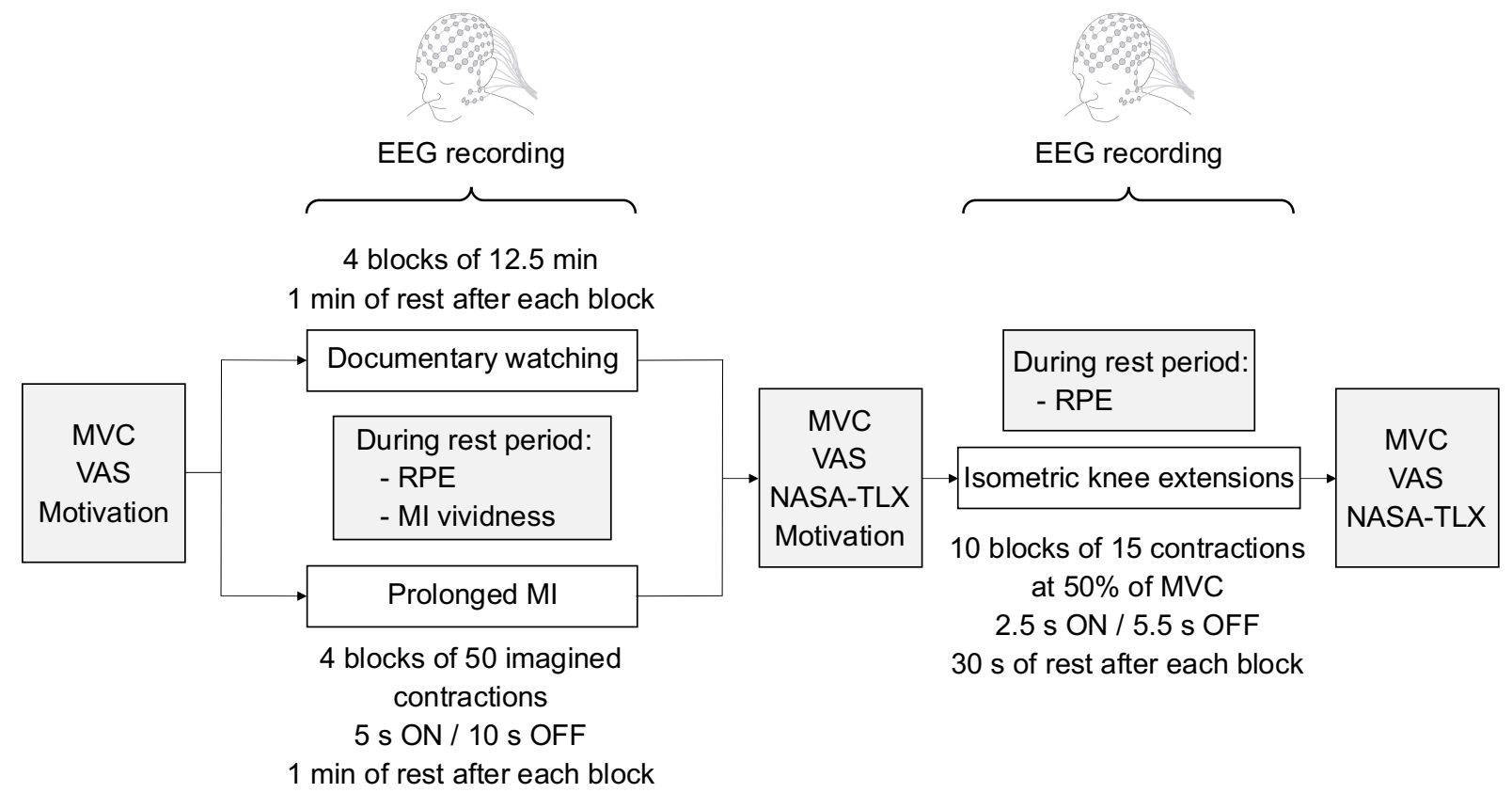

Figure 1. Overview of the experimental protocol.

Order and timing were the same for each participant and each session. VAS = fatigue visual analogue scale, $\mathrm{RPE}=$ rating of perceived effort, $\mathrm{MI}=$ motor imagery, $\mathrm{MVC}=$ maximal voluntary contraction, $\mathrm{NASA}-\mathrm{TLX}=$ National Aeronautics and Space Administration Task Load Index.

\section{3. EXPERIMENTAL TASKS}

\section{3. 1. PROLONGED MOTOR IMAGERY}

Prolonged MI consisted of four blocks of $12.5 \mathrm{~min}$ of kinesthetic MI for a total of approximately $50 \mathrm{~min}$. During imagined maximal isometric knee extensions, participants were instructed to perform kinesthetic MI and to perceive muscle contractions and joint tension with the same sensations they experienced during the completion of the previous MVC. Each participant was instructed to not contract her/his quadricep muscles during MI. An experimenter was seated behind the participant to check the EMG signal of the vastus lateralis muscle in order to control that the participant did not contract her/his muscle during imagined contractions. Participants performed MI, with their eyes closed, seated on the same isometric ergometer chair than the one used for the MVCs and intermittent isometric extensions of the knee extensors.

Participants performed four blocks of 50 imagined contractions of $5 \mathrm{~s}$, with a 10-s rest period between each imagined contraction and 1-min rest period between blocks (total duration of one 
block $=12.5 \mathrm{~min}$, total duration of prolonged $\mathrm{MI}=53 \mathrm{~min}$ ). Three instructions were given during prolonged MI. Two seconds before starting the imagined contraction participants heard "Get ready", then "Push" to start the imagined contraction, and "Relax" to stop the imagined contraction. The Experiment Builder software was used to time the instructions for each imagined contraction (SR Research). At the end of each block, perceived effort to accomplish prolonged MI and MI vividness were assessed.

\section{3. 2. CONTROL CONDITION}

The control condition consisted of watching an emotionally neutral documentary, "Home" by Y. Arthus-Bertrand, which was used as control condition in previous studies on mental fatigue (Le Mansec et al., 2018; Rozand et al., 2015). In these previous studies, it has been shown that this documentary did not induce any increase in subjective feeling of mental fatigue. Participants were sitting in a dark room on the same isometric ergometer chair than the one used for the intermittent MVCs of the knee extensors. The movie was projected on a screen placed $2 \mathrm{~m}$ in front of the participant. It was divided into four blocks of $12.5 \mathrm{~min}$ with $1 \mathrm{~min}$ of rest between each block to match with prolonged MI and to assess the perceived effort to watch the documentary.

\section{3. 3. PHYSICAL EXERCISE}

Following prolonged MI or watching the documentary, participants performed the physical exercise, which consisted in performing 150 submaximal isometric contractions of the right knee extensor muscles.

Beeps were presented as follows, a first beep to start the contractions and a second beep to stop the contractions. The contractions lasted $2.5 \mathrm{~s}$ with $5.5 \mathrm{~s}$ rest in between. Contractions were performed by blocks of 15 contractions interspaced by $25 \mathrm{~s}$ during which perception of effort was assessed.

Isometric contractions were performed at $50 \%$ of MVC $( \pm 5 \%)$. Visual feedback of the target strength was presented on a screen placed $2 \mathrm{~m}$ in front of the participant.

The Experiment Builder software was used to time the submaximal isometric contractions of the knee extensor muscles.

\section{4. PSYCHOLOGICAL MEASURES}




\section{4. 1. Motivation}

Motivation is defined as "the attribute that moves us to do or not to do something" (Gredler, 2001). Motivation has been proposed to influence performance (Richter et al., 2016) and interact with fatigue (Müller and Apps, 2019). Motivation to watch the documentary (control task), perform both motor imagery and physical exercise was measured with the motivation scale developed by Matthews et al., (2001). This questionnaire has seven questions on intrinsic motivation (e.g., "I

wish to do my best") and seven questions on extrinsic motivation (e.g., "I performed this exercise only because of an outside reward"). For each question, there are five possible answers ( $0=$ not at all, $1=$ a little bit, 2 = somewhat, 3 = very much, 4 = extremely). The score of each motivation ranges between 0 and 28 .

\section{4. 2. SUBJECTIVE WORKLOAD}

The National Aeronautics and Space Administration Task Load Index (NASA-TLX) was used to evaluate subjective workload (Hart and Staveland, 1988). The NASA-TLX is composed of six subscales: mental demand (how much mental and perceptual activity was required?), physical demand (how much physical activity was required?), temporal demand (how much time pressure did you feel due to the rate or pace at which the task occurred?), performance (how much successful do you think you were in accomplishing the goals of the task set by the experimenter?), effort (how hard did you have to work to accomplish your level of performance?), and frustration (how much irritating, annoying did you perceive the task?). The participants had to score each of the items on a scale divided into 20 equal intervals anchored by a bipolar descriptor (e.g. high/low). This score was multiplied by 5 , resulting in a final score between 0 and 100 for each of the subscales.

\section{4. 3. MENTAL FATIGUE LEVEL}

A visual analogue scale (VAS) was used to measure feelings of mental fatigue before and after prolonged MI and documentary watching. The VAS consisted of a line measuring $100 \mathrm{~mm}$ in length, with bipolar end anchors ( $0 \mathrm{~mm}=$ "No tired at all"; $100 \mathrm{~mm}=$ "Extremely tired"). The following question was asked to access the level of mental fatigue : "What is your feeling of mental fatigue right now?". Participants were asked to place a mark along the line to indicate how they currently felt. VAS score is defined by the distance between the first anchor $(0 \mathrm{~mm}$ : "No tired at all") and the mark placed by the participant. 


\section{4. 4. MOTOR IMAGERY VIVIDNESS}

MI vividness is defined as the clarity of the kinesthetic sensations elicited by MI (Saimpont et al., 2012). Participant had to evaluate their MI vividness on a Likert scale ( $1=$ "Not clear at all", 1 = "Very unclear", 3 = "Unclear", 4 = "Moderately clear", $5=$ "Quite clear", $6=$ ="Clear" $7=$ "Very clear"). This measure, performed each 50 imagined contractions, allows monitoring the evolution of MI vividness.

\section{4. 5. PERCEPTION OF EFFORT}

Perception of effort is defined as the conscious sensation of "how hard, heavy and strenuous a physical task is" (Marcora, 2010, 2009; Pageaux, 2016). During each task, participants reported the intensity of the effort invested. The intensity of perceived effort was reported with a modified version of the CR100 scale (Borg and Kaijser, 2006). This scale ranges from 0 (Nothing at all) to 100 (Maximal) and includes verbal anchors such as Weak/Light (13), Moderate (25), Strong/Heavy (50) or Very Strong (70). Modifications on the scale were made on the anchoring 0 and 100 to include the word effort in the description as follow: $0=$ No effort at all ;100 = Maximal effort.

During prolonged MI and documentary watching, participants were asked each 12.5 min to answer the following question: "How hard and intense is it for you to imagine the contractions (or watch the documentary)?". During the physical task, participants were asked at the end of each block to answer the following question: "How hard and intense is it for you to drive your leg?".

The scale allows values above 100 to be specified if the participant perceives an effort higher than the "Maximal exertion" (i.e., rating 100). Each participant was provided verbal examples of "No exertion" (e.g., not doing any cognitive work or sitting on the couch relaxing) and "Maximal exertion" (e.g., the most intense effort experienced in their life during prior cognitive activities or the sensations perceived during an MVC).

\section{5. Physiological Measurement}

\section{5. 1. FORCE RECORDING}

Right knee extension force was recorded using a homemade isometric ergometer that comprised a machine typically used for strength training connected to two strain gauges (STC 250 kg; sensitivity: $2.9997 \mathrm{mV} / \mathrm{V}$; Celtron Technologies Inc., Santa Clara, CA, USA) (Matkowski et al., 2011). The signal force was recorded with a commercially available software (AcqKnowledge 
4.1 for MP Systems, Biopac Systems Inc., Goleta, CA, USA). Knee angle was fixed at $100^{\circ}$ to perform isometric knee extensions $\left(0^{\circ}=\right.$ full knee extension $)$.

Force data were analyzed offline using Matlab (The Mathworks, Natick, MA). The onset and offset of the muscle contractions were determined automatically based on the positive and negative peaks in the second differential of the force signal (5th-order Bessel low-pass filter). For each contraction (i.e., from the onset to the offset of muscle force signal), a time window of $500 \mathrm{~ms}$ was used to calculate the mean force. This $500 \mathrm{~ms}$ was defined as $250 \mathrm{~ms}$ around the middle of the contraction. Rate of Force Development (RFD) was calculated for each submaximal contraction as the average slope of the force-time curve (force/time) over the time interval 0-200 ms (Aagaard et al., 2002). The onset of force production was defined as the time point where the force exceeded the baseline by $2 \mathrm{SD}$. The baseline is calculated on a 1-second sliding window during the rest period previous each contraction. The offset of force production was defined as the point time where the force became lower than the baseline +2 SD Mean force and RFD during the submaximal trials were averaged over the first (contractions 1 to 75 ) and the second half (contractions 76 to 150) of the trials.

Force tremor, which represents the variability in force production during intermittent contractions, was calculated as the force coefficient of variation (CV). For each contraction (i.e., from the onset to the offset of muscle force signal), a time window of $1.5 \mathrm{~s}$ was used to calculate the force tremor. This $1.5 \mathrm{~s}$ was defined as $750 \mathrm{~ms}$ around the middle of the contraction.

\section{5. 2. EMG RECORDING}

Electromyography (EMG) activity of the vastus lateralis was recorded with a pair of bipolar silver chloride circular (recording diameter of $10 \mathrm{~mm}$ ) surface electrodes (Swaromed, Nessler Medizintechnik, ref 1066, Innsbruck, Austria) with an interelectrode (center-to-center) distance of $20 \mathrm{~mm}$. The vastus lateralis muscle was chosen as representative of quadriceps muscle activity (Place et al., 2007). Low resistance between the two electrodes was obtained by shaving the skin and the skin was cleaned with alcohol. The electrodes were placed as close as possible to the patella for the vastus lateralis. The position of the electrodes followed the direction of the muscle fibers, according to the SENIAM recommendations (Hermens et al., 2000), and was aligned in the longitudinal direction of the muscle fibers. The reference electrode was placed on the ipsilateral patella. Myoelectrical signal was amplified with a bandwidth frequency ranging from 10 to $500 \mathrm{~Hz}$ 
(gain $=1000)$, digitized on-line at a sampling frequency of $2 \mathrm{kHz}$, and recorded with commercially available software (AcqKnowledge 4.1 for MP Systems, Biopac Systems Inc., Goleta, CA, USA).

The Root Mean Square (RMS) of the vastus lateralis EMG signal was calculated for each contraction from the onset to the offset of the EMG burst. The onset of muscle activity was considered to occur when the amplitude of the RMS-processed EMG exceeded +3 SD above the baseline EMG activity (mean activity calculated during a 400-ms time period immediately before impact). Thus, the contraction duration was defined as the time elapsed between the onset and the offset of EMG activation. The resulting values were averaged over the first half (contractions 1 to 75 ) and the second half (contractions 76 to 150 ) of the contractions.

\section{5. 3. EEG DATA}

The electroencephalogram was recorded at 64-scalp sites using a 10-20 system (BioSemi ActiveTwo). Horizontal eye movements were monitored with electrodes placed on the outer left and right canthi. Vertical eye movements were monitored with an electrode placed under the left eye. Two additional electrodes were placed on the left and right mastoids (A1, A2). During recording, the BioSemi ActiveTwo system's common-mode sense electrode served as the reference electrode. Each electrode was filled with Signa gel for improving signal transduction. Electrophysiological signals were digitized at a 2,048 $\mathrm{Hz}$ sampling rate and acquired with ActiView software. From the instructions given for imagined contractions and from the two beeps used for actual contractions, triggers were automatically reported on the EEG recording to signal the beginning and the end of each actual and imagined contraction. A trigger was also reported on the EEG recording when the participant had to prepare to imagine a movement. The EEG signals were analyzed using the EEGLAB (version 14.1) toolbox for Matlab (https://sccn.ucsd.edu/wiki/EEGLAB) (Delorme and Makeig, 2004).

Offline, data were re-referenced against the mean of electrodes A1 and A2 and downsampled to $512 \mathrm{~Hz}$. EEG data were filtered with a 0.01 to $5 \mathrm{~Hz}$ band-pass filter for MRCP analysis, while a 1 to $40 \mathrm{~Hz}$ band-pass filter was performed for spectral analyses. To correct for eye movement artifacts, EEGLAB's runica routine was used to perform independent component analyses. Noisy electrodes were identified with the probability method in $\operatorname{EEGLAB~}(Z=5)$ and interpolated when necessary with a spherical method. EEG signals were segmented into 150 epochs of 8,000 ms each (from 2,500 ms before to 5,500 ms after beep tone) for actual contractions, and into 200 epochs of 
$15,000 \mathrm{~ms}$ each (from $2,500 \mathrm{~ms}$ before to $12,500 \mathrm{~ms}$ after contraction onset) for imagined contractions. All trials were baseline corrected with $-2,500 \mathrm{~ms}$ to $-2,000 \mathrm{~ms}$. These epochs were used for MRCP analyses. During MI, MRCP amplitudes were averaged for each block (Block 1: imagined contractions 1 to 50, Block 2: imagined contractions 51 to 100, Block 3: imagined contractions 101 to 150 , Block 4: imagined contractions 151 to 200). During actual contractions, MRCP amplitudes were averaged over the first half (contractions 1 to 75 ) and the second half (contractions 76 to 150) of the physical exercise. During the physical exercise, the MRCPs obtained during contractions producing a force above $\pm 5 \%$ of the target force were excluded from the analysis. A visual inspection was also performed on all epochs, including actuals and imagined contractions, to remove contractions associated with movement artefacts (e.g., head movements).

EEG power was divided into five frequency bands: delta, $1-4 \mathrm{~Hz}$; theta, $4-7 \mathrm{~Hz}$; alpha, $8-12$ $\mathrm{Hz}$; beta $13-30 \mathrm{~Hz}$; and gamma, 30-40 Hz. Spectral data were analyzed during the first $5 \mathrm{~min}$ and the last $5 \mathrm{~min}$ of the prolonged MI and documentary watching. To observe changes in brain activation all over the scalp, we used nine regions of interests (ROIs) as previously suggested by Arendsen et al., (2020): Anterior Left (mean of FP1, AF3, AF7, F3, F5, F7, FC3, FC5, FT7), Anterior Median (mean of FPz, AFz, F1, Fz, F2, FC1, FCz, FC2), Anterior Right (mean of FP2, AF4, AF8, F4, F6, F8, FC4, FC6, FT8), Central Left (mean of C3, C5, T7, CP3, CP5, TP7), Central

Median (mean of C1, Cz, C2, CP1, CPz, CP2), Central Right (mean of C4, C6, T8, CP4, CP6, TP8), Posterior Left (mean of P9, P7, P5, P3, PO7, PO3, O1), Posterior Median (mean of P1, Pz, P2, POz, Oz), and Posterior Right (mean of P4, P6, P8, PO4, PO8, O2).

\section{6. STATISTICS}

All data are presented as means \pm SE.

Paired $t$-tests were used to assess the effect of condition (Prolonged MI, Control) on motivation and NASA-TLX scores.

One-way repeated measures ANOVAs were used to test the effect of time (4 blocks of 12.5 min) on imagery vividness and MRCP amplitude during prolonged MI. Two-way repeatedmeasures $2 \times 4$ ANOVAs were used to test the effects of condition (Prolonged MI, Control) and time ( 4 blocks of $12.5 \mathrm{~min}$ ) on perceived effort. Two-way repeated-measures $2 \times 2$ ANOVAs were used to test the effects of condition (Prolonged MI, Control) and time (First 5 min, Last $5 \mathrm{~min}$ ) on delta, theta, alpha, beta, and gamma power during prolonged MI and documentary watching. To 
test the effects of prolonged MI on force production capacity, a two-way repeated-measures $2 \times 2$ ANOVA was used to test the effects of condition (Prolonged MI, Control) and time (Pre, Post 1) on MVC.

Two-way repeated-measures $2 \times 2$ ANOVAs were used to test the effects of condition (MI, Control) and time (First part: contractions 1 to 75, Second part: contractions 76 to 150) on the numbers of MRCPs analyzed, the MRCP amplitude, rating of perceived effort, force, RFD, tremor, and contraction duration during physical exercise. To test the effect of the physical exercise on force production capacity, a two-way repeated-measures $2 \times 2$ ANOVA was used to test the effects of condition (Prolonged MI, Control) and time (Post 1, Post 2) on MVC.

Greenhouse-Geisser correction to the degrees of freedom was applied when violations of sphericity were present (corrected degree of freedom and $p$-values are reported). For ANOVAs, when significant, main effects and condition $\times$ time interaction were followed up with Bonferroni tests as appropriate.

Partial eta squared are reported, and thresholds for small, moderate, and large effects were set at 0.01, 0.07, and 0.14, respectively (Cohen, 1988). Analyses were conducted using JASP (version 0.10.2.0 for Windows). For paired $t$-tests, Cohen's $d z$ were calculated using G*Power software (version 3.1.6, Universität Düsseldorf, Germany) and thresholds for small, moderate and large effects were set at $0.2,0.5$, and 0.8 respectively (Cohen, 1988). Correlations were performed between perception of effort and MRCP amplitude for both the imagined and actual contractions, with the R package 'rmcorr' assessing repeated measures correlation (Bakdash and Marusich, 2017; Bland and Altman, 1995). Level of significance was set at $p<.05$ (two-tailed).

\section{RESULTS}

Due to excessive head movements, one participant was excluded from the analyses related to the physical exercise. Therefore, the sample size was $N=13$ for analyses related to the prolonged MI or the control condition (watching a documentary), and $n=12$ for analyses related to the physical exercise.

\section{1. Mental Fatigue ASSESSMENT}




\section{1. 1. EFFECTS OF PROLONGED MOTOR IMAGERY ON PSYCHOLOGICAL MEASUREMENTS}

Motivation to perform prolonged MI or watch the documentary did not differ for extrinsic $\left(t_{(12)}=-0.267, p=.794, d z=.077\right.$; Prolonged MI: $15.9 \pm 1.3$, Control condition: $\left.16.1 \pm 1.2\right)$ and intrinsic $\left(t_{(12)}=-1.945, p=.076, d z=.538\right.$; Prolonged MI: $17.6 \pm 1.0$, Control condition: $19.0 \pm$ 0.9) motivation.

The effects of prolonged MI and the documentary watching on feelings of fatigue, perception of effort, subjective workload and MI vividness are displayed in Figure 2. Feelings of fatigue (Figure 2.A) increased over time $\left(F_{(1,12)}=18.306, p=.001, \eta_{p}^{2}=.604\right)$, with no significant main effect of condition $\left(F_{(1,12)}=1.563, p=.235, \eta_{p}^{2}=.115\right)$ or condition $\times$ time interaction $\left(F_{(1}\right.$, 12) $\left.=3.464, p=.087, \eta_{p}^{2}=.224\right)$. Perception of effort (Figure 2.B), was greater in the Prolonged MI condition compared to the Control condition $\left(F_{(1,12)}=10.518, p=.007, \eta_{p}^{2}=.467\right)$ and increased over time $\left(F_{(1.311,15.732)}=16.637, p<.001, \eta_{p}^{2}=.581\right)$. A condition $\times$ time interaction $\left(F_{(1.443,17.319)}\right.$ $\left.=8.256, p=.006, \eta_{p}^{2}=.408\right)$ revealed that the effort required to imagine the contractions increased over time and was significantly higher at Block $3\left(t_{(12)}=-5.448, p<.001, d z=-1.248\right)$ and Block $4\left(t_{(12)}=-8.141, p<.001, d=-1.117\right)$ compared to Block 1 . The effort reported to watch the documentary did not change over time (all $p s>.20$, all $d z<.95$ ). The effort reported to imagine contractions compared to watch the documentary was reported as significantly greater solely at Block $4\left(t_{(12)}=-8.141, p=.008, d z=-1.226\right)$.

Analyses on the reported subjective workload (Figure 2.C) revealed a greater mental demand $\left(t_{(12)}=5.556, p<.001, d z=1.541\right)$, physical demand $\left(t_{(12)}=2.456, p=.030, d z=0.681\right)$, temporal demand $\left(t_{(12)}=2.379, p=.035, d z=.660\right)$ and performance $\left(t_{(12)}=4.573, p<.001, d z=\right.$ 1.268) following completion of prolonged MI compared to the documentary watching. However, the subscales frustration $\left(t_{(12)}=-.623, p=.545, d z=-.171\right)$ and effort $\left(t_{(12)}=2.060, p=.062, d z=\right.$ .571) did not change significantly.

MI vividness (Figure 2.D) decreased over time $\left(F_{(1.490,17.877)}=8.163, p=.024, \eta_{p}^{2}=.301\right)$. As shown with the comparison with Block 1 (vs. Block 2: $t_{(12)}=0.617, p=1.000, d z=0.171$; vs. Block 3: $t_{(12)}=1.339, p=1.000, d z=0.385$; vs. Block 4: $\left.t_{(12)}=2.449, p=0.184, d z=0.679\right)$, and Block 2 vs. Block $4\left(t_{(12)}=3.395, p<.032, d=0.942\right)$, the decrease in MI vividness occurred towards the end of second half of the prolonged MI. 

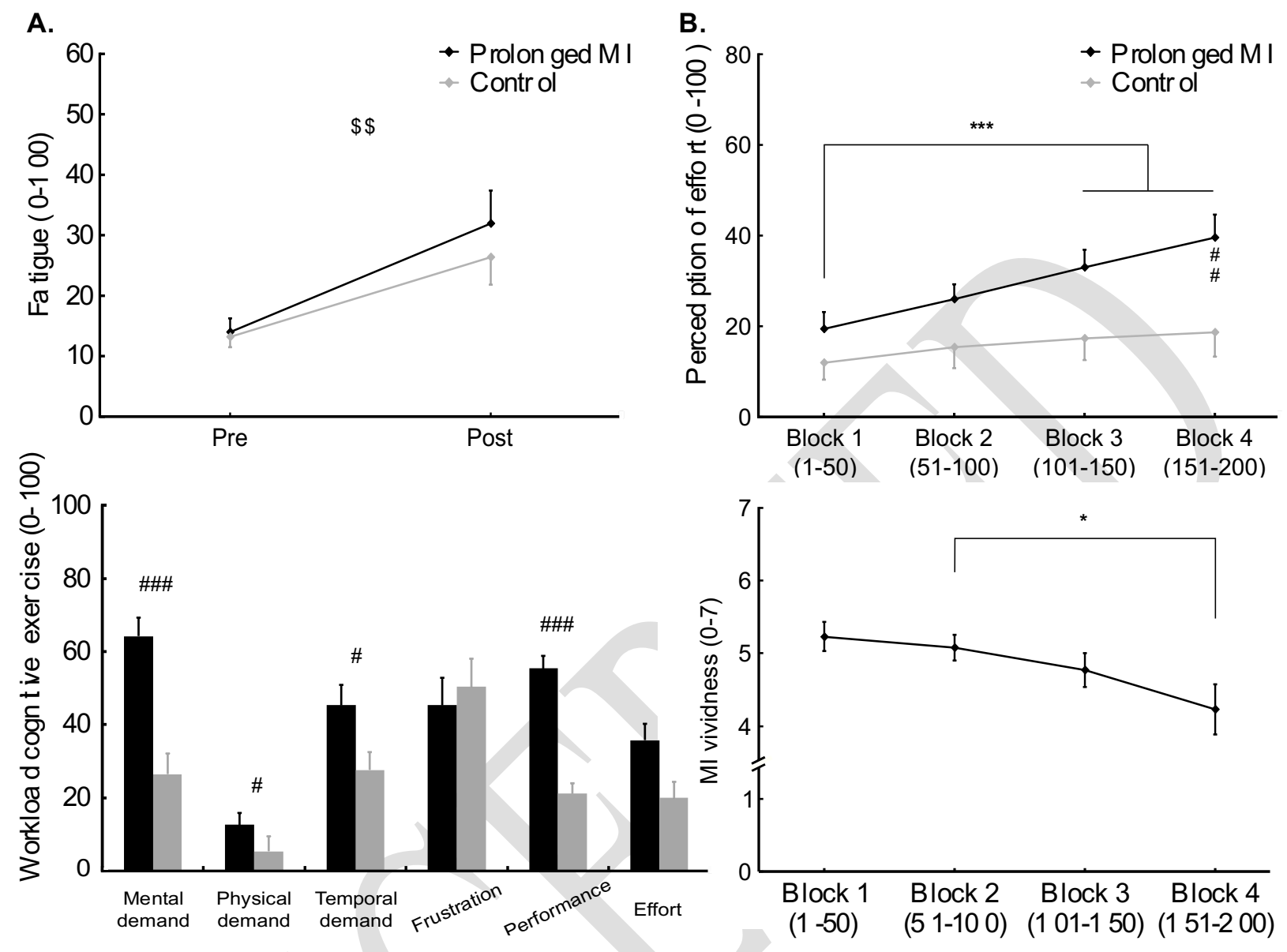

Figure 2. Feelings of fatigue (panel A), rating of perceived effort to perform prolonged motor imagery (MI) and to watch the documentary (Control condition) (panel B), subjective workload of the prolonged MI and control task, and rating of MI vividness during prolonged MI evaluated with a Likert scale (panel D). \$\$: Significant main effect of time $(p<.01)$. $^{*}$ and, ***: Significant difference between two time points within the same condition $(p<$ .05 and, $p<.001)$. \#, \#\# and, \#\#\#: Significant difference between conditions at the same time of measurement $(p<$

$.05, p<.01$ and, $p<.001)$. Data are presented as means $\pm \operatorname{SE}(N=13)$.

\section{1. 2. EFFECTS OF PROLONGED MOTOR IMAGERY ON NEUROPHYSIOLOGICAL MEASUREMENTS}

\section{Force production capacity}

The force production capacity of the knee extensors decreased over time $\left(F_{(1,12)}=11.050\right.$, $\left.\mathrm{p}=.006, \eta_{p}^{2}=.479\right)$ with no main effect of condition $\left(F_{(1,12)}<.001, \mathrm{p}=.992, \eta_{p}^{2}<.001\right)$ or condition $\times$ time interaction $\left(F_{(1,12)}=1.141, \mathrm{p}=.306, \eta_{p}^{2}=.086\right.$; Prolonged MI condition: $206.9 \pm 15.9 \mathrm{~N}$ to $195.6 \pm 14.3 \mathrm{~N}$, Control condition: $204.2 \pm 16.6 \mathrm{~N}$ to $198.1 \pm 16.9 \mathrm{~N})$. 


\section{Brain oscillations analysis}

All the results on brain oscillations are presented in the Supplementary data (Table S1). Significant differences related to alpha power and theta power are presented below.

Theta (4-7 Hz). Theta power at the Parietal Left region decreased over time $\left(F_{(1,11)}=6.250\right.$, $p=.030, \eta_{p}^{2}=.362$ ). For all ROIs, no significant interaction was observed (all $p s>.25$, all $\eta_{p}^{2}<$ $.119)$.

Alpha (8-12 Hz). A greater alpha power was observed in the Prolonged MI condition compared to the Control condition at the Frontal Median $\left(F_{(1,11)}=9.057, p=.012, \eta_{p}^{2}=.452\right)$, Central Median $\left(F_{(1,11)}=7.876, p=.017, \eta_{p}^{2}=.417\right)$, and Central Right $\left(F_{(1,11)}=11.477, p=.006\right.$, $\left.\eta_{p}^{2}=.511\right)$, Parietal Left $\left(F_{(1,11)}=11.423, p=.006, \eta_{p}^{2}=.509\right)$, Parietal Median $\left(F_{(1,11)}=15.867\right.$, $\left.p=.002, \eta_{p}^{2}=.591\right)$, and Parietal Right $\left(F_{(1,11)}=13.700, p=.003, \eta_{p}^{2}=.555\right)$ regions. However, for all ROIs, no significant interaction was reported (all $p s>.30$, all $\eta_{p}^{2}<.098$ ).

\section{$>$ Motor and premotor area activity}

$99.8 \pm 0.1 \%$ of imagined contractions were analysed. During prolonged MI, MRCP amplitude at $\mathrm{Cz}$ electrode (Figure 3.) increased over time $\left(F_{(3,36)}=4.259, p=.011, \eta_{p}^{2}=.262\right)$ ). As shown with the comparison with Block 1 (vs. Block 2: $t_{(12)}=-0.569, p=1.000, d z=-0.158$; vs. Block 3: $\left.t_{(12)}=-3.050, p=.060, d z=-0.846\right)$, MRCP amplitude at $\mathrm{Cz}$ progressively increased up to significance at Block $4\left(t_{(12)}=-4.358, p=.006, d z=-1.242\right)$. The repeated measures correlation analysis revealed a significant correlation between MRCP amplitude and perception of effort during imagined contractions $(r(38)=.369, p=.019)$. 
A.

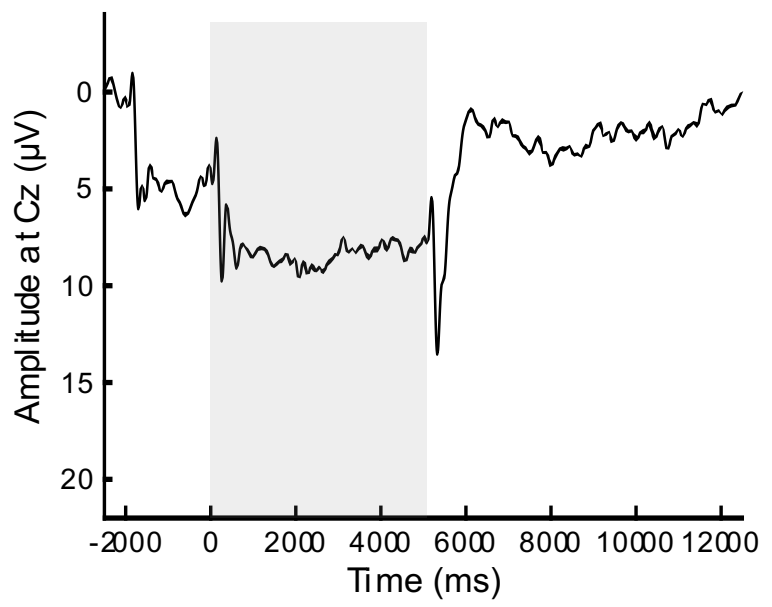

C.

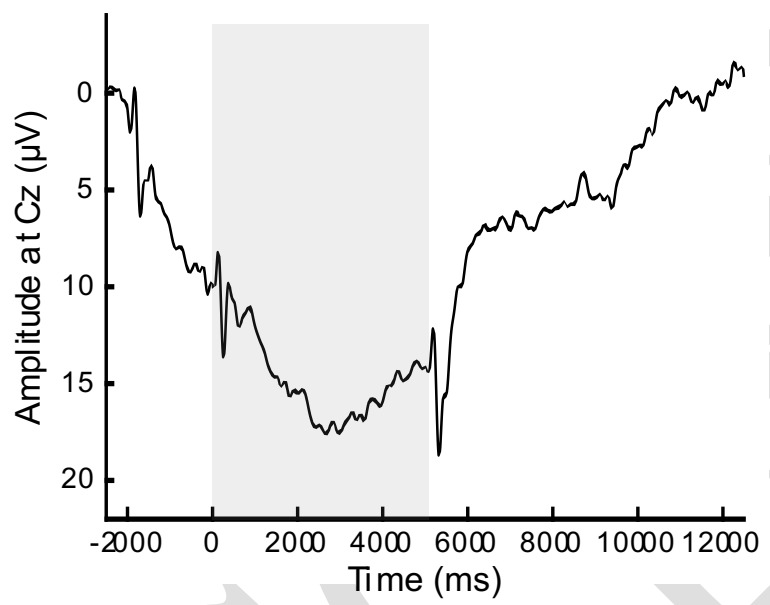

E.

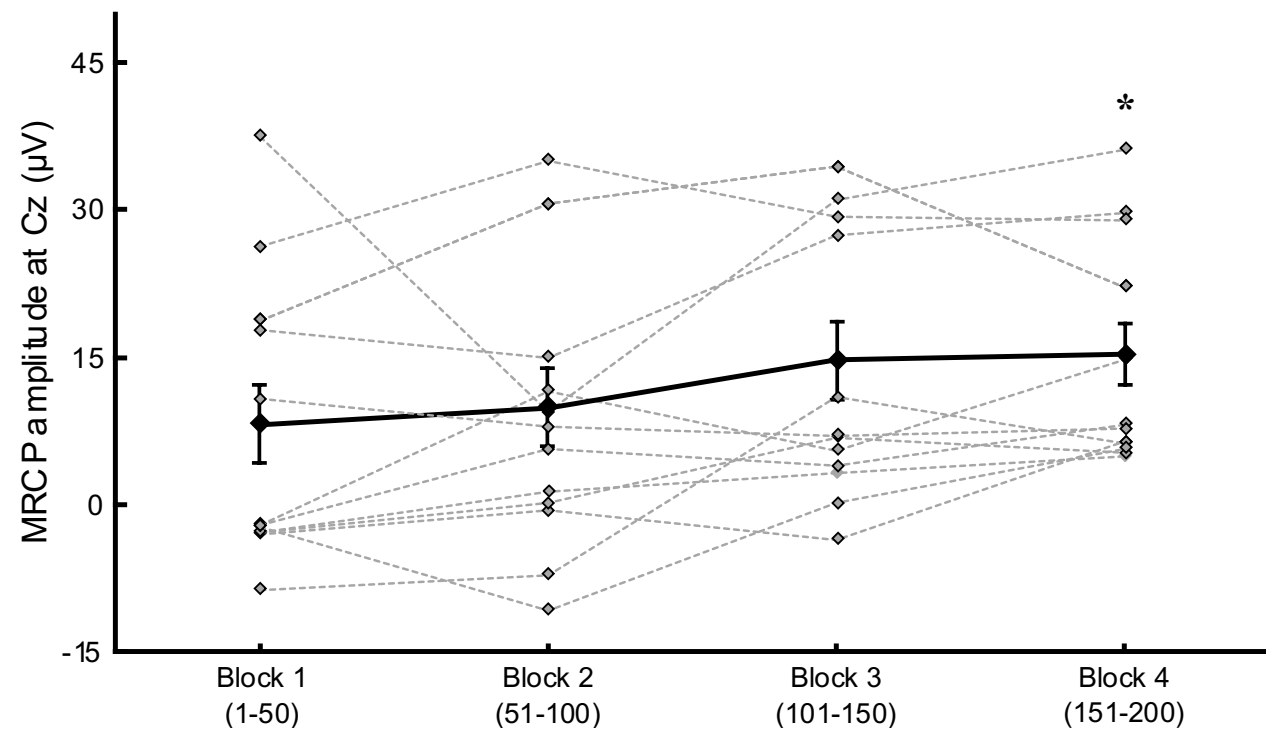

B. $\quad$ Block $2(51-100)$

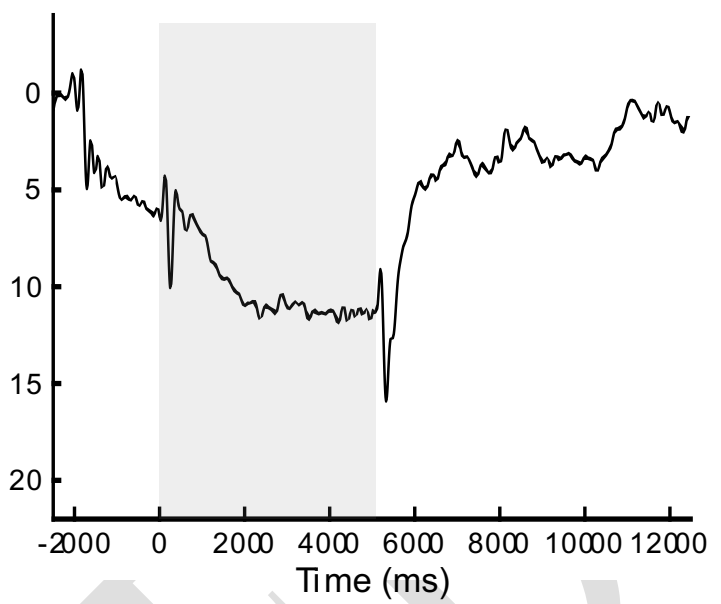

D.

Block 4 (151-200)

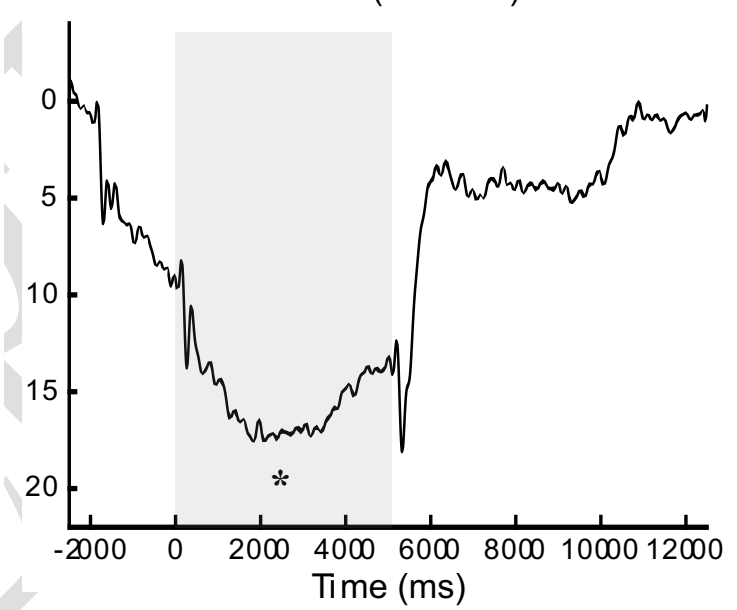


isometric right knee extensions. Time 0 corresponds to the audio signal to start the contraction (panels $\mathrm{A}, \mathrm{B}, \mathrm{C}$, and D), and the shaded area on the panels A, B, C and D represents the time window used for the analysis of the MRCP amplitude. Individual values of MRCP for each participants (panel E; grey bars indicate individual values and dark bars indicate averaged values). *: Significantly different from Block $1(p<.05)$.

\section{2. EFFECTS OF MENTAL FATIGUE INDUCED BY PROLONGED MOTOR IMAGERY ON PHYSICAL EXERCISE}

Motivation to perform physical exercise did not differ between conditions for intrinsic $\left(t_{(12)}\right.$ $=0.217, p=.832, d z=.026$; Prolonged MI: $18.8 \pm 1.3$, Control condition: $18.7 \pm 1.2$ ) or extrinsic motivation $\left(t_{(12)}=-0.378, p=.713, d z=-.111\right.$; Prolonged MI: $16.9 \pm 1.2$, Control condition: $16.8 \pm$ $1.5)$.

\section{2. 1. Psyghological Changes}

The NASA TLX scale (Figure 4.A) revealed that in the Prolonged MI condition, participants reported a greater physical demand compared to the Control condition $\left(t_{(11)}=2.185, p\right.$ $=.049, d z=.639)$. No difference was reported for mental demand, temporal demand, performance, effort and frustration subscales (all $p \mathrm{~s}>.70$, all $|d z|<.45$ ).

Perception of effort (Figure 4.B) increased over time $\left(F_{(1,11)}=65.466, p<.001, \eta_{p}^{2}=.856\right)$, and was higher in the Prolonged MI condition compared to the Control condition $\left(F_{(1,11)}=5.320\right.$, $\left.p=.042, \eta_{p}^{2}=.326\right)$. The condition $\times$ time interaction $\left(F_{(1,11)}=6.922, p=.023, \eta_{p}^{2}=.386\right)$ revealed a greater increase in perceived effort over time following prolonged $\mathrm{MI}\left(t_{(11)}=-8.432, p<.001, d z\right.$ $=-2.458)$ compared to watching a documentary $\left(t_{(11)}=-6.151, p<.001, d z=-1.758\right)$. No significant difference between conditions $\left(t_{(11)}=-.906, p=1.000, d z=-.262\right)$ was observed during the first part of the physical exercise. During the second part of the physical exercise, perception of effort was higher in the Prolonged MI condition compared to Control condition $\left(t_{(11)}=-3.232, p=.031\right.$, $d z=-.933)$. 
A.

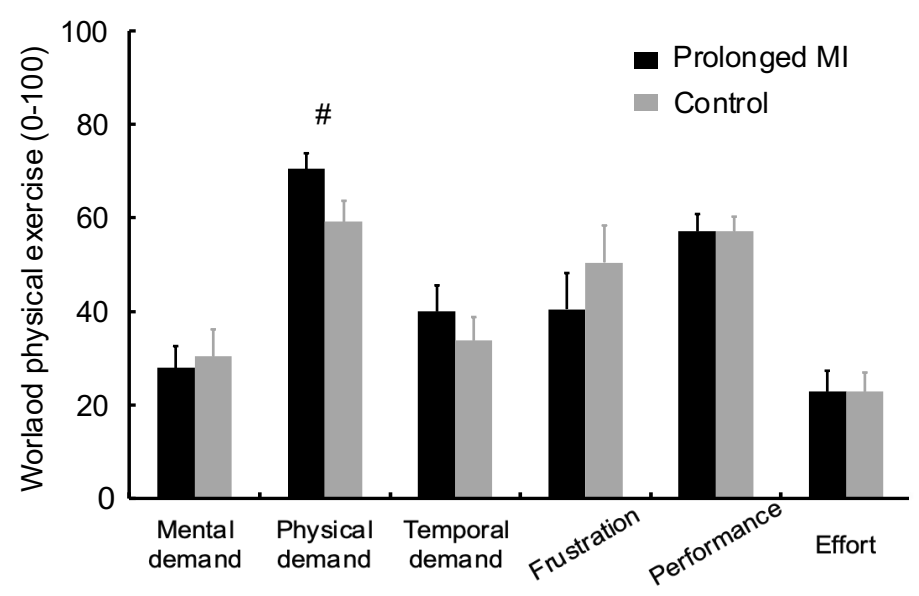

B.

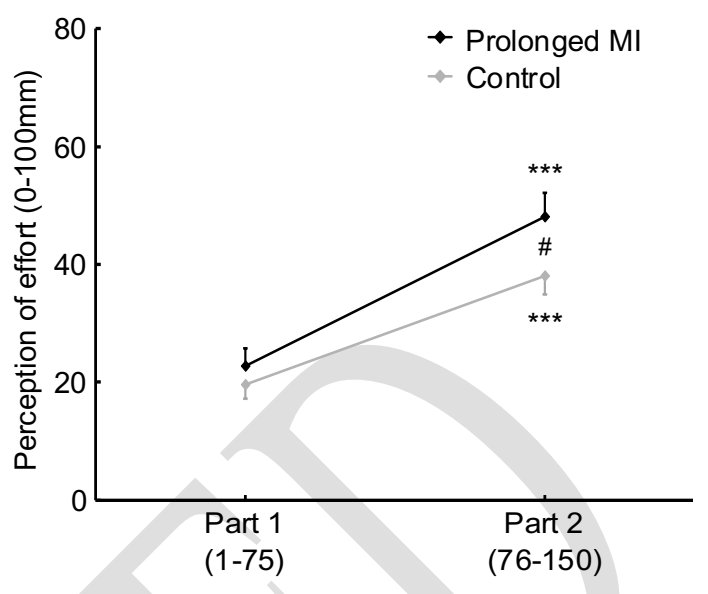

Figure 4. Results for the subjective workload (NASA-TLX) (panel A) and the rating of perceived effort to perform the physical exercise following prolonged MI (black) and documentary watching (grey). \#: Significant difference between conditions at the same time of measurement $(p<.05)$. $* * *$ : Significant difference between two time points within the same condition $(p<.001)$. Data are presented as means $\pm \operatorname{SE}(n=12)$.

\section{2. 2. Physiological Changes}

\section{Neuromuscular changes}

The 150 right knee isometric contractions induced a decrease in force production capacity $\left(F_{(1,11)}=22.323, p<.001, \eta_{p}^{2}=.670\right)$ with no difference between conditions $\left(F_{(1,11)}=1.068, p\right.$ $\left.=.324, \eta_{p}^{2}=.088\right)$ and no significant condition $\times$ time interaction $\left(F_{(1,11)}=3.522, p=.087, \eta_{p}^{2}=\right.$ .243; Prolonged MI condition: $195.6 \mathrm{~N} \pm 15.5$ to $167.0 \mathrm{~N} \pm 12.4$, Control condition: $196.1 \mathrm{~N} \pm 18.2$ to $175.8 \mathrm{~N} \pm 14.0$ ).

Neuromuscular responses to the physical exercise, results of the ANOVAs, and the relevant follow-up tests are presented in Table 1. Neuromuscular responses did not differ between conditions, except for the VL EMG RMS. The condition $\times$ time interaction $\left(F_{(1,11)}=8.711, p=\right.$ $\left..013, \eta_{p}^{2}=.442\right)$ revealed an increase solely in the Prolonged MI condition $\left(t_{(11)}=-2.976, p=.054\right.$, $d z=-0.859)$ and not in the Control condition $\left(t_{(11)}=-0.377, p=.713, d z=-0.109\right)$. 


\begin{tabular}{|c|c|c|c|c|c|c|c|}
\hline \multirow{2}{*}{ Variables } & \multicolumn{2}{|c|}{ Prolonged MI } & \multicolumn{2}{|c|}{ Control } & \multirow{2}{*}{$\begin{array}{c}\text { Condition } \\
p\left(\eta_{p}^{2}\right)\end{array}$} & \multirow{2}{*}{$\begin{array}{c}\text { Time } \\
p\left(\eta_{p}^{2}\right)\end{array}$} & \multirow{2}{*}{$\begin{array}{c}\text { Interaction } \\
p\left(\eta_{p}^{2}\right)\end{array}$} \\
\hline & Part $1(0-75)$ & Part 2 (76-150) & Part $1(0-75)$ & Part 2 (76-150) & & & \\
\hline Force $(N)$ & $105.7 \pm 8.1$ & $104.9 \pm 7.9$ & $104.4 \pm 7.9$ & $104.1 \pm 7.8$ & $.473(.048)$ & $.297(.098)$ & $.405(.064)$ \\
\hline $\begin{array}{c}\text { RFD mean } \\
(\mathrm{N} / \mathrm{s})\end{array}$ & $271.8 \pm 40.7$ & $272.8 \pm 45.3$ & $286.2 \pm 30.2$ & $273.9 \pm 39.1$ & $.798(.006)$ & $.721(.012)$ & $.576(.029)$ \\
\hline Tremor (\%) & $2.23 \pm 0.40$ & $2.33 \pm 0.31$ & $2.15 \pm 0.29$ & $2.17 \pm 0.23$ & $.736(.011)$ & $.802(.006)$ & $.905(.001)$ \\
\hline $\begin{array}{l}\text { Contraction } \\
\text { duration (s) }\end{array}$ & $2.88 \pm 0.04$ & $2.85 \pm 0.03$ & $2.91 \pm 0.05$ & $2.93 \pm 0.05$ & $.405(.064)$ & $.844(.004)$ & $.110(.215)$ \\
\hline $\begin{array}{l}\text { VL EMG RMS } \\
\text { (\% RMS max) }\end{array}$ & $30.3 \pm 2.2$ & $32.7 \pm 2.6$ & $30.9 \pm 2.7$ & $31.2 \pm 2.9$ & $.827(.005)$ & $.089(.241)$ & $.013(.442)$ \\
\hline
\end{tabular}

Table 1. Mean force, rate of force development (RFD), tremor, contraction duration, and vastus lateralis (VL) EMG RMS during the isometric knee extensions, during the first part (contractions 1 to 75 ) and the second part (contractions 76 to 150) of the physical exercise in Prolonged MI and Control conditions. Data are presented as means $\pm \operatorname{SE}(n=12)$.

\section{Motor and premotor area activity}

For the MRCP amplitude analysis, $18.3 \pm 0.9$ contractions per part of the exercise were excluded due to an incorrect force development and $2.4 \pm 0.9$ due to the presence of movement artefacts. In total, $72.4 \pm 1.3 \%$ of the total number of contractions were included in the statistical analysis. The numbers of contractions analyzed did not differ between the experimental conditions $\left(F_{(1,11)}=4.009, p=.071, \eta_{p}^{2}=.267\right)$ and did not change over time $\left(F_{(1,11)}=0.920, p=.358, \eta_{p}^{2}=\right.$ $.077)$. The condition $\times$ time interaction was also not significant $\left(F_{(1,11)}=0.044, p=.838, \eta_{p}^{2}=.004\right)$.

MRCP amplitude at $\mathrm{Cz}$ during the physical exercise (Figure 5) increased over time $\left(F_{(1,11)}\right.$ $\left.=10.325, p=.008, \eta_{p}^{2}=.484\right)$ with no main effect of condition $\left(F_{(1,11)}=2.222, p=.164, \eta_{p}^{2}=.168\right)$ or condition $\times$ time interaction $\left(F_{(1,11)}=3.832, p=.076, \eta_{p}^{2}=.258\right)$. As shown in Figure 5B and $5 \mathrm{C}, \mathrm{MRCP}$ amplitude responses to the actual contractions presented a notable variability. The repeated measures correlation analysis failed to reveal a significant correlation between MRCP amplitude and perception of effort for actual contractions $(r(35)=.311, p=.060)$. 
A.

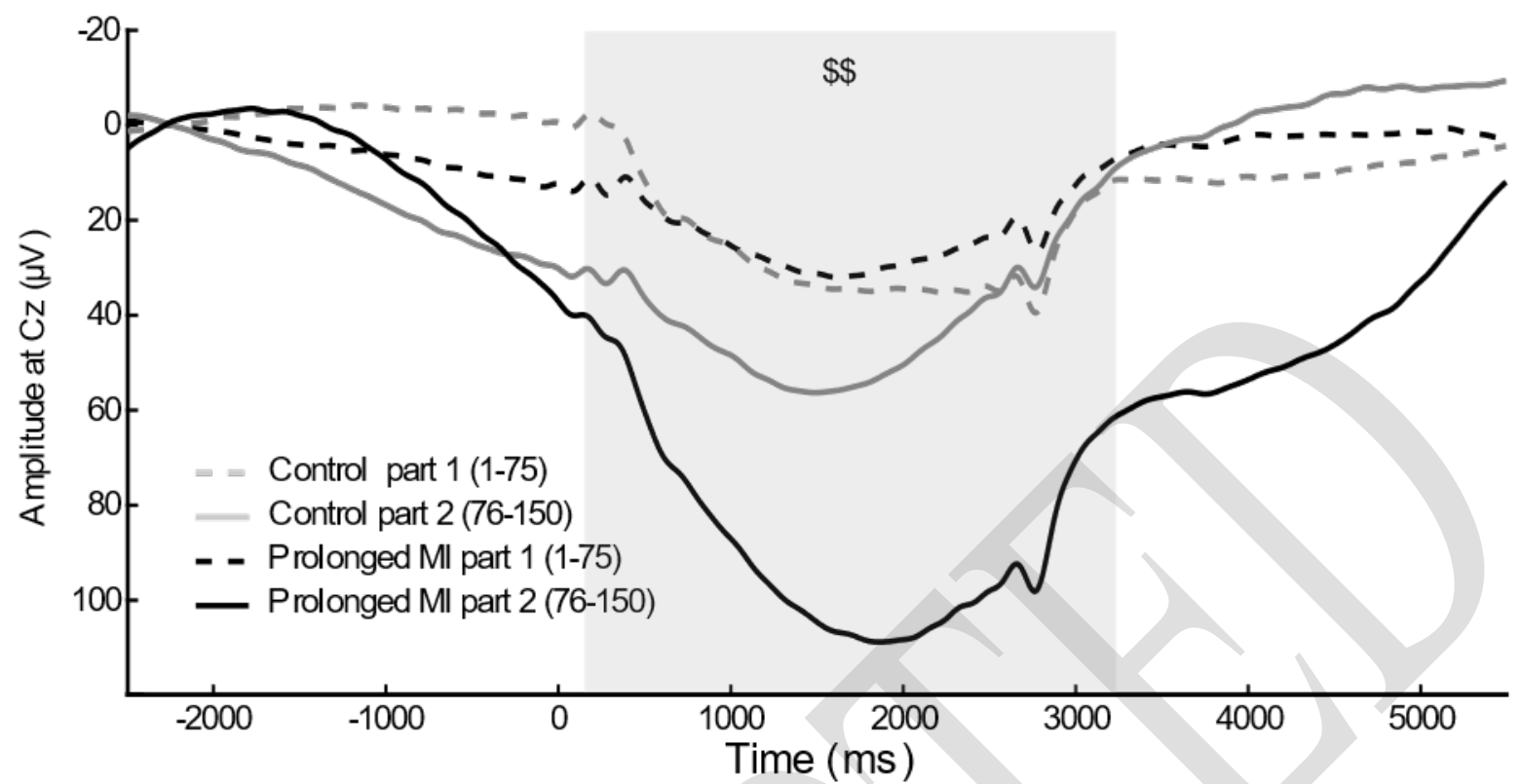

B.

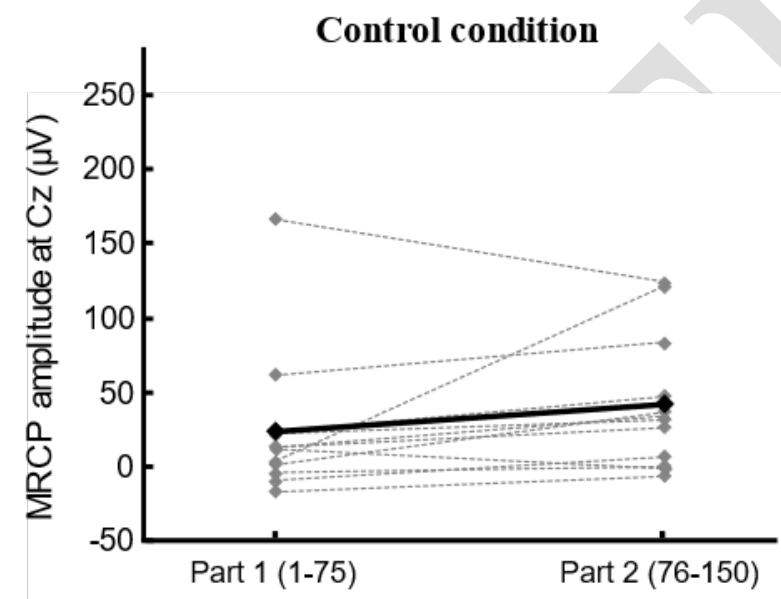

C.

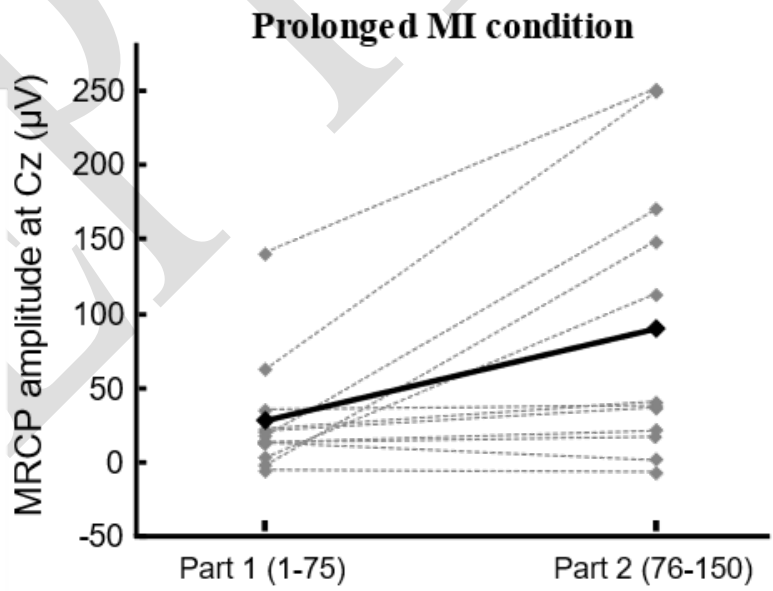

Figure 5. Grand average $(n=12)$ of the EEG signal amplitude at $\mathrm{Cz}$ electrode for the first part (contractions 1 to 75$)$ and the second part (contractions 76 to 150) of the submaximal isometric right knee extensions in both Prolonged MI and Control conditions. Time 0 corresponds to the audio signal to start the contraction (panel A), and the shaded area on the panel A represents the time window used for the analyse of the MRCP amplitude as presented in panels B and C. Individual mean amplitude of MRCP for the first and the second part of isometric knee extensions in the Control condition (panel B) and in the Prolonged MI condition (panel C). \$\$: Significant main effect of time on MRCP amplitude $(p<.01)$. 


\section{DISCUSSION}

The main aim of the present study was to confirm that, when prolonged, motor imagery could induce a state of mental fatigue. The progressive increase in motor and premotor area activity required to imagine the contractions, in combination with the decreased quality of motor imagery and the increased feelings of fatigue, confirms that prolonged motor imagery induces mental fatigue. The secondary aim of the study was to identify during a subsequent physical exercise neurophysiological alterations caused by mental fatigue. While this study confirms previous observations that perception of effort during a physical exercise is increased in the presence of mental fatigue (for review see: Pageaux and Lepers, 2018; Brown et al., 2020), the results of the analysis of the MRCP amplitude cannot firmly confirm that this higher perceived effort is related to greater activation of the motor and premotor areas required to perform the isometric knee extensions. As discussed thereafter, this study needs to be replicated with specific adjustments on the physical exercise protocol to limit the exercise-induced decrease in force production capacity. Such adjustments will facilitate the possibility to observe clearer specific alterations in MRCP amplitude related to mental fatigue during an actual physical exercise.

\section{1. EVIDENCE OF MOTOR IMAGERY}

When requiring participants to engage in motor imagery, it is difficult to assess whether they actually imagine and execute the task. The greater alpha power during the prolonged motor imagery condition compared to the control condition, as well as the higher effort and mental demand experienced during the prolonged motor imagery condition, suggest the involvement of different cognitive processes during both prolonged motor imagery and documentary watching (Beyer et al., 1990). As previously observed, the imagination of maximal voluntary contractions was associated with the presence of MRCPs, confirming a specific activation of motor and premotor areas (do Nascimento et al., 2006; Jankelowitz and Colebatch, 2002). The MRCP amplitudes at Cz electrode during the imagined contractions were smaller than during the actual contractions $(M=12.00 \mu \mathrm{V}$ vs. $M=45.56 \mu \mathrm{V}$ ). This result is in line with neuroimaging studies reporting lower activation of motor and premotor areas during imagined contractions compared to actual contractions (Batula et al., 2017; Porro et al., 1996). Furthermore, it is important to note that the absence of EMG activity during the imagination of contractions confirms that the participants imagined without activating 
their knee extensors. The integration of these results altogether confirms that the participants accurately performed motor imagery.

\section{2. EVIDENCE OF MENTAL FATIGUE INDUCED BY PROLONGED MOTOR IMAGERY}

Mental fatigue is characterized by subjective feelings of "tiredness" and "lack of energy", associated or not with a decrease in cognitive performance (Boksem and Tops, 2008; Brown et al., 2020; Pageaux and Lepers, 2018). Mental fatigue is also known to increase the effort required to perform cognitive or physical activities (Nolte et al., 2008; Pageaux and Lepers, 2016). In the present study, feelings of fatigue increased over time, and the quality of motor imagery measured with the report of motor imagery vividness decreased during the prolonged motor imagery session, suggesting that prolonged motor imagery induces mental fatigue. The induction of mental fatigue by engagement in prolonged motor imagery is also confirmed by the progressive increase in the effort required to imagine the contractions over time.

In the present study, both the prolonged motor imagery and documentary watching increased feelings of fatigue. While the lack of significant condition $\times$ time interaction on the reported feelings of fatigue refrains the firm conclusion that the prolonged motor imagery condition induced a greater level of mental fatigue than the control condition, it is important to note that the participants experienced more effort to perform the subsequent physical exercise in the prolonged motor imagery condition compared to the control condition. A higher than normal perception of effort during a physical exercise is a well-reported alteration induced by the presence of mental fatigue (for review see: Pageaux and Lepers, 2018; Brown et al., 2020). Therefore, by considering that i) the effort required to perform motor imagery or watching a documentary increased solely in the prolonged motor imagery condition, and ii) the effort required to perform the subsequent physical exercise increased solely in the prolonged motor imagery condition, we are confident that the level of mental fatigue was greater following prolonged motor imagery compared to watching a documentary for the same duration. As boredom and sleepiness are proposed to interact with mental fatigue, it cannot be excluded that the observed increase in feelings of fatigue in the control condition confounds with changes in boredom and/or sleepiness, as recently suggested (O'Keeffe et al., 2020). As feelings of fatigue and boredom (Pattyn et al., 2008), as well as feelings of fatigue and sleepiness (Shen et al., 2006), can be dissociated from each other, future studies inducing mental fatigue should monitor the changes in these three constructs during prolonged engagement 
in demanding cognitive tasks. Such approach is likely to open new opportunities for researchers interested in better understanding the neurophenomenological differences between the experience of fatigue, boredom and sleepiness.

\section{3. ARE BRAIN OSCILLATIONS A GOOD MARKER OF MENTAL FATIGUE INDUCED BY PROLONGED MOTOR IMAGERY?}

The analysis of brain oscillations recorded with electroencephalography is a well-used marker of mental fatigue induced by prolonged engagement in demanding cognitive tasks. A recent meta-analysis reported that changes in brain oscillations on the theta and alpha power are consistently observed in the presence of mental fatigue (Tran et al., 2020). Prolonged engagement in demanding cognitive tasks has been shown to increase the oscillations on both alpha (e.g., Craig et al., 2012) and theta (e.g., Wascher et al., 2014) power. In the present study, no significant main effect of time or condition $\times$ time interaction was reported for the oscillations of the alpha power, suggesting that the completion of prolonged motor imagery did not induce a specific change over time in this parameter. Also, contrary to the hypothesis expecting an increased theta power in the presence of mental fatigue, the oscillations of the theta power decreased over time in the left parietal region. The observed changes in the oscillations of the theta power and the lack of changes in the oscillations of the alpha power do not support the possibility to use changes in brain oscillations as a marker of mental fatigue induced by prolonged motor imagery. These results are in line with a recent study showing that the engagement in different cognitive tasks leading to mental fatigue (psychomotor vigilance task, AX-CPT and Stroop task) does not elicit clear effects on EEG responses (Smith et al., 2019). The integration of our results with those of Smith et al (2019) suggests that future studies should aim at identifying EEG-markers of mental fatigue that could provide coherent responses between different tasks known to induce a state of mental fatigue.

\section{4. PROLONGED MOTOR IMAGERY INCREASES THE MOTOR AND PREMOTOR AREA ACTIVITY REQUIRED TO IMAGINE MUSCLE CONTRACTIONS}

While the analysis of brain oscillations was not successful to identify the presence of mental fatigue, this study is to the best of our knowledge, the first to identify a neurophysiological alteration caused by mental fatigue induced by prolonged motor imagery. The progressive increase in MRCP amplitude suggests that a greater motor and premotor area activity is required to imagine muscle contractions in the presence of mental fatigue. It is therefore plausible that mental fatigue induces alterations in the motor command required to accurately perform imagined or actual 
muscle contractions. The hypothesis of an altered motor command in the presence of mental fatigue has been originally reported in a previous study demonstrating alterations in the speed-accuracy trade-off in the presence of mental fatigue (Rozand et al., 2015). In this study, the authors observed a longer duration of actual and imagined movements during a pointing task performed following 90 min of an incongruent Stroop task, compared to watching an emotionally neutral documentary for the same duration. In the present study, the observed increase in MRCP amplitude in the presence of mental fatigue, as well as the correlation between MRCP amplitude and perception of effort, provides neurophysiological evidence that mental fatigue could increase the magnitude of the motor command required to imagine a movement, and supports the hypothesis of an altered motor command in the presence of mental fatigue proposed by Rozand et al. (2015).

While the present study confirms that prolonged motor imagery induces mental fatigue, it is crucial to acknowledge that motor imagery is an efficient tool in rehabilitation when its use is not prolonged. By integrating the results of the objective (increase in MRCP amplitude over time) and subjective (increase in the effort required to imagine the contractions over time and decreased motor imagery vividness) markers of mental fatigue, our results reconcile with the recent metaanalysis of Schuster et al. (2011) suggesting that $\sim 17$ minutes of motor imagery is optimal to observe positive effects on physical performance. Indeed, in the present study, significant alterations in the effort required to perform imagined contractions was apparent after $25 \mathrm{~min}$ of motor imagery (i.e., from Block 3). By integrating the results of the meta-analysis of Schuster et al. (2011) with the results of the present study, future studies willing to use motor imagery and control for mental fatigue induction should use motor imagery sessions lasting no longer than 20 $\min$.

\section{5. EFFECTS OF MENTAL FATIGUE INDUCED BY PROLONGED MOTOR IMAGERY ON A SUBSEQUENT PHYSICAL EXERCISE}

As observed in previous studies, performing repeated muscle contractions for a prolonged duration induces a decrease in force production capacity that in turn increases the effort required to perform the physical exercise (Gandevia, 2001). This decrease in force production capacity highlights the presence of neuromuscular fatigue (Gandevia, 2001) and explains the increase in perception of effort and MRCP amplitude during the second half of the physical exercise in both prolonged motor imagery and control conditions (de Morree et al., 2014, 2012). Indeed, as perception of effort during physical exercise reflects the neuronal process of the motor command 
(de Morree et al., 2014, 2012; Pageaux, 2016; Pageaux and Gaveau, 2016), producing the same absolute level of force in the presence of neuromuscular fatigue requires an increased motor command to counteract the negative effects of neuromuscular fatigue on the corticospinal pathway and recruit additional muscle fibers (de Morree et al., 2012; Pageaux, 2016).

Contrary to previous studies demonstrating a higher perceived effort at the onset of the physical exercise performed in the presence of mental fatigue (Pageaux et al., 2015, 2014, 2013), in the present study the effort reported by the participants during the first half of the physical exercise did not differ between the prolonged motor imagery and the control conditions. Perception of effort was greater in the presence of mental fatigue solely in the second half of the physical exercise. As the studies observing a higher effort at the onset of the physical exercise used cognitive tasks predominantly involving the response inhibition process and not prolonged motor imagery, the discrepancy in these results suggests that mental fatigue may have different effects on a physical exercise depending on the method used to induce it. It can be speculated that, the absence of difference in perceived effort in the first half of the physical exercice could be due to the positive immediate effects of an acute motor imagery session on corticospinal plasticity (Ruffino et al., 2019). It cannot be excluded that the positive effects of motor imagery on the corticospinal pathway could counteract at the onset of the physical exercise the negative effects of mental fatigue on subsequent physical performance. Further studies should investigate a duration-response relationship on the effects of a single session of motor imagery on subsequent physical performance.

\section{6. EFFECT OF MENTAL FATIGUE ON MOTOR AND PREMOTOR AREA ACTIVITY}

Perception of effort is proposed to be generated by the neuronal process of a corollary discharge of the motor command (de Morree et al., 2014, 2012; Pageaux, 2016; Pageaux and Gaveau, 2016), and is traditionally used in the neurophysiology literature as a marker of the central motor command (e.g., Kjær et al., 1999; McCloskey et al., 1974; Mitchell et al., 1989; Seed et al., 2019). Muscle activation measured with EMG is traditionally used as a marker of the motor command sent to the working muscles in studies interested in the regulation of muscle contractions and movements (e.g., Carrier et al., 2011; Thoroughman and Shadmehr, 1999). The vastus lateralis EMG RMS increased solely in the prolonged motor imagery condition and not in the control condition. The specific alterations in objective (EMG) and subjective (perception of effort) indices 
of the motor command suggest that prolonged motor imagery alters the motor command in a subsequent physical exercise, and that underlying neurophysiological alterations progressively develop over time. However, both the nonsignificant condition $\times$ time interaction on the analysis of the MRCP amplitude and the nonsignificant correlation between MRCP amplitude and perception of effort do not allow to clearly conclude on that point. The observed variability in changes in MRCP amplitude during the physical exercise performed following prolonged motor imagery (Figure 5.C) also suggests between-participant differences in response to mental fatigue. Although all participants declared to engage in a physical activity at least one time per week, their exact training status and sport expertise was not collected. As expertise in endurance sports seems to be associated with greater resistance to mental fatigue (Martin et al., 2016), the variability observed in changes in MRCP amplitude could be due to differences between participant in training status, sport expertise or physical activity level. In this context, studies interested in investigating mental fatigue should carefully record at least the physical activity level of their participants, and if possible their sport expertise and associated performance level (Decroix et al., 2016; Pauw et al., 2013).

As previous studies also observed alterations in EMG signal of the working muscles during submaximal physical exercices following engagement in demanding cognitive tasks (Bray et al., 2008; Graham et al., 2014; Pageaux et al., 2015), we believe that the absence of significance in the condition $\times$ time interaction is likely due to the confounding effects of neuromuscular fatigue on MRCP amplitude (de Morree et al., 2014, 2012) rather than the absence of a true effects of mental fatigue on this parameter. Indeed, as a reduction in force production capacity is known to increase MRCP amplitude (de Morree et al., 2012), and our physical exercise induced a decrease in force production capacity, future studies should be conducted by tailoring the physical exercise to limit as much as possible the presence of exercise-induced neuromuscular fatigue. As the magnitude of neuromuscular fatigue is known to be intensity and contraction duration dependent (Burnley et al., 2012; Mendez-Villanueva et al., 2009), such tailoring could be done by decreasing the level of the relative force target to reach during each contraction or the duration of the contractions, as well as by increasing the recovery period between the contractions. Such changes in the physical exercise protocol are also likely to reduce the number of excluded MRCPs due to head or body movement during the muscle contractions. Even if knee extensions were investigated for their relevance to locomotion and other activities of the daily life in this study, these contractions involve a large 
muscle group and generate large artifacts on the EEG signal. Therefore, we also suggest that future studies should consider involving a smaller muscle group and perform movements such as elbow flexions, wrist flexions or handgrip contractions. Involving a smaller muscle group compared to the knee extensors, or decreasing the intensity of the physical exercise, will also reduce cardiorespiratory responses to the physical exercise (Mitchell et al., 1980) and render the physical exercise more accessible to various populations and not only physically active and healthy young adults. Finally, we acknowledge that the limit of our sample size does not allow to clearly conclude on the condition $\times$ time interaction on the MRCP amplitude during the physical exercise $(p=.076$ ,$\eta_{p}^{2}=.258$ ) performed following the prolonged motor imagery. An increased sample size in future studies is i) likely to overcome this limitation and ii) of great importance for studies interested in gender and sex differences in the effect of mental fatigue on subsequent physical performance.

\section{7. CONCLUSION AND PERSPECTIVES}

The present study confirms that, when prolonged, motor imagery induces a state of mental fatigue. The presence of mental fatigue was evidenced by the progressive increase in motor and premotor area activity required to imagine the contractions (i.e., increase in MRCP amplitude over time), in combination with the decreased quality of motor imagery and the increased feelings of fatigue. In the presence of mental fatigue induced by prolonged motor imagery, the subsequent physical exercise was perceived as being more effortful in the second part of the exercise and was associated with a specific increase in EMG RMS of the vastus lateralis muscle. These alterations suggest that mental fatigue induced by prolonged motor imagery may alter the motor command required to perform imagined and actual contractions. However, due to the marked decrease in knee extensors force production capacity induced by the physical exercise and consequently its confounding effects on the observed increase in MRCP amplitude (de Morree et al., 2012), future studies will be necessary to replicate and reinforce the results of the present study, notably by tailoring the physical exercise to avoid, or at least minimize, neuromuscular fatigue. 


\section{REFERENCES}

Aagaard, P., Simonsen, E.B., Andersen, J.L., Magnusson, P., Dyhre-Poulsen, P., 2002. Increased rate of force development and neural drive of human skeletal muscle following resistance training. J. Appl. Physiol. 93, 1318-1326. https://doi.org/10.1152/japplphysiol.00283.2002

Amann, M., Light, A.R., 2014. Reply: To PMID 24142455. Exp. Physiol. 99, 836. https://doi.org/10.1113/expphysiol.2014.078832

Arendsen, L.J., Henshaw, J., Brown, C.A., Sivan, M., Taylor, J.R., Trujillo-Barreto, N.J., Casson, A.J., Jones, A.K.P., 2020. Entraining alpha activity using visual stimulation in patients with chronic musculoskeletal pain: A feasibility study. Front. Neurosci. https://doi.org/10.3389/fnins.2020.00828

Bakdash, J.Z., Marusich, L.R., 2017. Repeated measures correlation. Front. Psychol. https://doi.org/10.3389/fpsyg.2017.00456

Bart, V.K.E., Koch, I., Rieger, M., 2020. Decay of inhibition in motor imagery. Q. J. Exp. Psychol. 1747021820949388. https://doi.org/10.1177/1747021820949388

Barwick, F., Arnett, P., Slobounov, S., 2012. EEG correlates of fatigue during administration of a neuropsychological test battery. Clin. Neurophysiol. 123, 278-284. https://doi.org/10.1016/j.clinph.2011.06.027

Bates, J.A. V., 1951. Electrical activity of the cortex accompanying movement. J. Physiol. 113, 240-257. https://doi.org/10.1113/jphysiol.1951.sp004569

Batula, A.M., Mark, J.A., Kim, Y.E., Ayaz, H., 2017. Comparison of brain activation during motor imagery and motor movement using fNIRS. Comput. Intell. Neurosci. 2017, 1-12. https://doi.org/10.1155/2017/5491296

Beyer, L., Weiss, T., Hansen, E., Wolf, A., Seidel, A., 1990. Dynamics of central nervous activation during motor imagination. Int. J. Psychophysiol. 9, 75-80. https://doi.org/10.1016/01678760(90)90008-2

Bland, J.M., Altman, D.G., 1995. Statistics notes: Calculating correlation coefficients with repeated observations: Part 1 correlation within subjects. BMJ 310, 446. https://doi.org/10.1136/bmj.310.6977.446

Boksem, M.A., Tops, M., 2008. Mental fatigue: Costs and benefits. Brain Res. Rev. 59, 125-139. https://doi.org/10.1016/j.brainresrev.2008.07.001

Borg, E., Kaijser, L., 2006. A comparison between three rating scales for perceived exertion and two different work tests. Scand. J. Med. Sci. Sport. 16, 57-69. https://doi.org/10.1111/j.16000838.2005.00448.x

Bray, S.R., Martin Ginis, K.A., Hicks, A.L., Woodgate, J., 2008. Effects of self-regulatory strength depletion on muscular performance and EMG activation. Psychophysiology 45, 337-343. https://doi.org/10.1111/j.1469-8986.2007.00625.x

Brown, D.M.Y., Graham, J.D., Innes, K.I., Harris, S., Flemington, A., Bray, S.R., 2020. Effects of prior cognitive exertion on physical performance: A systematic review and meta-analysis. 
Sport. Med. 50, 497-529. https://doi.org/10.1007/s40279-019-01204-8

Broxterman, R.M., Layec, G., Hureau, T.J., Morgan, D.E., Bledsoe, A.D., Jessop, J.E., Amann, M., Richardson, R.S., 2018. Response. Med. Sci. Sports Exerc. https://doi.org/10.1249/MSS.0000000000001606

Burnley, M., Vanhatalo, A., Jones, A.M., 2012. Distinct profiles of neuromuscular fatigue during muscle contractions below and above the critical torque in humans. J. Appl. Physiol. 113, 215-223. https://doi.org/10.1152/japplphysiol.00022.2012

Carrier, D.R., Anders, C., Schilling, N., 2011. The musculoskeletal system of humans is not tuned to maximize the economy of locomotion. Proc. Natl. Acad. Sci. 108, 18631-18636. https://doi.org/10.1073/pnas.1105277108

Chholak, P., Niso, G., Maksimenko, V.A., Kurkin, S.A., Frolov, N.S., Pitsik, E.N., Hramov, A.E., Pisarchik, A.N., 2019. Visual and kinesthetic modes affect motor imagery classification in untrained subjects. Sci. Rep. 9, 9838. https://doi.org/10.1038/s41598-019-46310-9

Cho, H., Kim, J., Lee, G.-C., 2013. Effects of motor imagery training on balance and gait abilities in post-stroke patients: a randomized controlled trial. Clin. Rehabil. 27, 675-680. https://doi.org/10.1177/0269215512464702

Cohen, J., 1988. Statistical power analysis for the behavioural science (2nd Edition), Statistical Power Anaylsis for the Behavioral Sciences.

Craig, A., Tran, Y., Wijesuriya, N., Nguyen, H., 2012. Regional brain wave activity changes associated with fatigue. Psychophysiology 49, 574-582. https://doi.org/10.1111/j.14698986.2011.01329.x

de Morree, H.M., Klein, C., Marcora, S.M., 2014. Cortical substrates of the effects of caffeine and time-on-task on perception of effort. J. Appl. Physiol. 117, 1514-1523. https://doi.org/10.1152/japplphysiol.00898.2013

de Morree, H.M., Klein, C., Marcora, S.M., 2012. Perception of effort reflects central motor command during movement execution. Psychophysiology 49, 1242-1253. https://doi.org/10.1111/j.1469-8986.2012.01399.x

Decety, J., 1996a. The neurophysiological basis of motor imagery. Behav. Brain Res. 77, 45-52. https://doi.org/10.1016/0166-4328(95)00225-1

Decety, J., 1996b. Do imagined and executed actions share the same neural substrate? Cogn. Brain Res. 3, 87-93. https://doi.org/https://doi.org/10.1016/0926-6410(95)00033-X

Decroix, L., De Pauw, K., Foster, C., Meeusen, R., 2016. Guidelines to classify female subject groups in sport-science research. Int. J. Sports Physiol. Perform. 11, 204-213. https://doi.org/10.1123/ijspp.2015-0153

Delorme, A., Makeig, S., 2004. EEGLAB: an open source toolbox for analysis of single-trial EEG dynamics including independent component analysis. J. Neurosci. Methods 134, 9-21. https://doi.org/10.1016/j.jneumeth.2003.10.009

do Nascimento, O.F. do, Nielsen, K.D., Voigt, M., 2006. Movement-related parameters modulate cortical activity during imaginary isometric plantar-flexions. Exp. Brain Res. 171, 78-90. 
https://doi.org/10.1007/s00221-005-0247-z

Duncan, M.J., Fowler, N., George, O., Joyce, S., Hankey, J., 2015. Mental fatigue negatively influences manual dexterity and anticipation timing but not repeated high-intensity exercise performance in trained adults. Res. Sport. Med. 23, 1-13. https://doi.org/10.1080/15438627.2014.975811

Gandevia, S.C., 2001. Spinal and supraspinal factors in human Muscle Fatigue. Physiol. Rev. 81, 1725-1789. https://doi.org/10.1152/physrev.2001.81.4.1725

Graham, J.D., Sonne, M.W.L., Bray, S.R., 2014. It wears me out just imagining it! Mental imagery leads to muscle fatigue and diminished performance of isometric exercise. Biol. Psychol. 103, 1-6. https://doi.org/10.1016/j.biopsycho.2014.07.018

Gredler, M.E., 2001. Learning and instruction : theory into practice, Fourth edi. ed. Upper Saddle River, NJ : Pearson Prentice Hall.

Grosprêtre, S., Jacquet, T., Lebon, F., Papaxanthis, C., Martin, A., 2018. Neural mechanisms of strength increase after one-week motor imagery training. Eur. J. Sport Sci. 18, 209-218. https://doi.org/10.1080/17461391.2017.1415377

Guillot, A., Collet, C., Nguyen, V.A., Malouin, F., Richards, C., Doyon, J., 2009. Brain activity during visual versus kinesthetic imagery: An fMRI study. Hum. Brain Mapp. 30, 2157-2172. https://doi.org/10.1002/hbm.20658

Hart, S.G., Staveland, L.E., 1988. Development of NASA-TLX (Task Load Index): Results of empirical and theoretical research, in: Advances in Psychology. pp. 139-183. https://doi.org/10.1016/S0166-4115(08)62386-9

Head, J., Tenan, M.S., Tweedell, A.J., LaFiandra, M.E., Morelli, F., Wilson, K.M., Ortega, S. V, Helton, W.S., 2017. Prior mental fatigue impairs marksmanship decision performance. Front. Physiol. 8, 680. https://doi.org/10.3389/fphys.2017.00680

Hermens, H.J., Freriks, B., Disselhorst-Klug, C., Rau, G., 2000. Development of recommendations for SEMG sensors and sensor placement procedures. J. Electromyogr. Kinesiol. 10, 361-374. https://doi.org/10.1016/S1050-6411(00)00027-4

Jackson, P.L., Lafleur, M.F., Malouin, F., Richards, C., Doyon, J., 2001. Potential role of mental practice using motor imagery in neurologic rehabilitation. Arch. Phys. Med. Rehabil. 82, 1133-1141. https://doi.org/10.1053/apmr.2001.24286

Jankelowitz, S., Colebatch, J., 2002. Movement-related potentials associated with self-paced, cued and imagined arm movements. Exp. Brain Res. 147, 98-107. https://doi.org/10.1007/s00221002-1220-8

Kjær, M., Hanel, B., Worm, L., Perko, G., Lewis, S.F., Sahlin, K., Galbo, H., Secher, N.H., 1999. Cardiovascular and neuroendocrine responses to exercise in hypoxia during impaired neural feedback from muscle. Am. J. Physiol. Integr. Comp. Physiol. 277, R76-R85. https://doi.org/10.1152/ajpregu.1999.277.1.R76

Kumar, V.K., 2016. Motor imagery training on muscle strength and gait performance in ambulant stroke subjects-a randomized clinical trial. J. Clin. Diagnostic Res. 10, YC01-YC04. 
https://doi.org/10.7860/JCDR/2016/16254.7357

Lal, S.K., Craig, A., 2002. Driver fatigue: Electroencephalography and psychological assessment. Psychophysiology 39, 313-321. https://doi.org/10.1017.S0048577201393095

Le Mansec, Y., Pageaux, B., Nordez, A., Dorel, S., Jubeau, M., 2018. Mental fatigue alters the speed and the accuracy of the ball in table tennis. J. Sports Sci. 36, 2751-2759. https://doi.org/10.1080/02640414.2017.1418647

Lebon, F., Guillot, A., Collet, C., 2012. Increased muscle activation following motor imagery during the rehabilitation of the anterior cruciate ligament. Appl. Psychophysiol. Biofeedback 37, 45-51. https://doi.org/10.1007/s10484-011-9175-9

MacMahon, C., Schücker, L., Hagemann, N., Strauss, B., 2014. Cognitive fatigue effects on physical performance during running. J. Sport Exerc. Psychol. 36, 375-381. https://doi.org/10.1123/jsep.2013-0249

Marcora, S., 2010. Effort: Perception of, in: EB Goldstein (Ed.), . SAGE Publications, pp. 380383.

Marcora, S., 2009. Perception of effort during exercise is independent of afferent feedback from skeletal muscles, heart, and lungs. J. Appl. Physiol. 106.

Marcora, S.M., Staiano, W., Manning, V., 2009. Mental fatigue impairs physical performance in humans. J. Appl. Physiol. 106, 857-864. https://doi.org/10.1152/japplphysiol.91324.2008

Martin, K., Staiano, W., Menaspà, P., Hennessey, T., Marcora, S., Keegan, R., Thompson, K.G., Martin, D., Halson, S., Rattray, B., 2016. Superior Inhibitory Control and Resistance to Mental Fatigue in Professional Road Cyclists. PLoS One 11, e0159907.

Matkowski, B., Martin, A., Lepers, R., 2011. Comparison of maximal unilateral versus bilateral voluntary contraction force. Eur. J. Appl. Physiol. 111, 1571-1578. https://doi.org/10.1007/s00421-010-1775-1

Matthews, G., Campbell, S.E., Falconer, S., 2001. Assessment of Motivational States in Performance Environments. Proc. Hum. Factors Ergon. Soc. Annu. Meet. 45, 906-910. https://doi.org/10.1177/154193120104501302

McCloskey, D.I., Ebeling, P., Goodwin, G.M., 1974. Estimation of weights and tensions and apparent involvement of a "sense of effort." Exp. Neurol. 42, 220-232. https://doi.org/10.1016/0014-4886(74)90019-3

Mendez-Villanueva, A., Baudry, S., Riley, Z.A., Rudroff, T., 2009. Influence of rest duration on muscle activation during submaximal intermittent contractions with the elbow flexor muscles. J. Sports Med. Phys. Fitness 49, 255-264.

Mitchell, J.H., Payne, F.C., Saltin, B., Schibye, B., 1980. The role of muscle mass in the cardiovascular response to static contractions. J. Physiol. 309, 45-54. https://doi.org/10.1113/jphysiol.1980.sp013492

Mitchell, J.H., Reeves, D.R., Rogers, H.B., Secher, N.H., 1989. Epidural anaesthesia and cardiovascular responses to static exercise in man. J. Physiol. 417, 13-24. https://doi.org/10.1113/jphysiol.1989.sp017787 
Müller, T., Apps, M.A.J., 2019. Motivational fatigue: A neurocognitive framework for the impact of effortful exertion on subsequent motivation. Neuropsychologia 123, 141-151. https://doi.org/10.1016/j.neuropsychologia.2018.04.030

Nolte, R.N., Wright, R.A., Turner, C., Contrada, R.J., 2008. Reported fatigue, difficulty, and cardiovascular response to a memory challenge. Int. J. Psychophysiol. 69, 1-8. https://doi.org/10.1016/j.ijpsycho.2008.02.004

O'Keeffe, K., Hodder, S., Lloyd, A., 2020. A comparison of methods used for inducing mental fatigue in performance research: individualised, dual-task and short duration cognitive tests are most effective. Ergonomics 63, 1-12. https://doi.org/10.1080/00140139.2019.1687940

O'Shea, H., Moran, A., 2017. Does motor simulation theory explain the cognitive mechanisms underlying motor imagery? A critical review. Front. Hum. Neurosci. 11, 72. https://doi.org/10.3389/fnhum.2017.00072

Pageaux, B., 2016. Perception of effort in exercise science: Definition, measurement and perspectives. Eur. J. Sport Sci. 16, 885-894. https://doi.org/10.1080/17461391.2016.1188992

Pageaux, B., Gaveau, J., 2016. Studies using pharmacological blockade of muscle afferents provide new insights into the neurophysiology of perceived exertion. J. Physiol. 594, 5049-5051. https://doi.org/10.1113/JP272585

Pageaux, B., Lepers, R., 2018. The effects of mental fatigue on sport-related performance, in: Marcora, S., Sarkar, M. (Eds.), Progress in Brain Research. pp. 291-315. https://doi.org/10.1016/bs.pbr.2018.10.004

Pageaux, B., Lepers, R., 2016. Fatigue induced by physical and mental exertion increases perception of effort and impairs subsequent endurance performance. Front. Physiol. 7, 587. https://doi.org/10.3389/fphys.2016.00587

Pageaux, B., Lepers, R., Dietz, K.C., Marcora, S.M., 2014. Response inhibition impairs subsequent self-paced endurance performance. Eur. J. Appl. Physiol. 114, 1095-1105. https://doi.org/10.1007/s00421-014-2838-5

Pageaux, B., Marcora, S.M., Lepers, R., 2013. Prolonged mental exertion does not alter neuromuscular function of the knee extensors. Med. Sci. Sport. Exerc. 45, 2254-2264. https://doi.org/10.1249/MSS.0b013e31829b504a

Pageaux, B., Marcora, S.M., Rozand, V., Lepers, R., 2015. Mental fatigue induced by prolonged self-regulation does not exacerbate central fatigue during subsequent whole-body endurance exercise. Front. Hum. Neurosci. 9, 67. https://doi.org/10.3389/fnhum.2015.00067

Pattyn, N., Neyt, X., Henderickx, D., Soetens, E., 2008. Psychophysiological investigation of vigilance decrement: Boredom or cognitive fatigue? Physiol. Behav. 93, 369-378. https://doi.org/10.1016/j.physbeh.2007.09.016

Pauw, K. De, Roelands, B., Cheung, S.S., de Geus, B., Rietjens, G., Meeusen, R., 2013. Guidelines to classify subject groups in sport-science research. Int. J. Sports Physiol. Perform. 8, 111122. https://doi.org/10.1123/ijspp.8.2.111

Place, N., Maffiuletti, N.A., Martin, A., Lepers, R., 2007. Assessment of the reliability of central 
and peripheral fatigue after sustained maximal voluntary contraction of the quadriceps muscle. Muscle Nerve 35, 486-95. https://doi.org/10.1002/mus.20714

Porro, C.A., Francescato, M.P., Cettolo, V., Diamond, M.E., Baraldi, P., Zuiani, C., Bazzocchi, M., di Prampero, P.E., 1996. Primary motor and sensory cortex activation during motor performance and motor imagery: A functional magnetic resonance imaging study. J. Neurosci. 16, 7688-7698. https://doi.org/10.1523/JNEUROSCI.16-23-07688.1996

Ranganathan, V.K., Siemionow, V., Liu, J.Z., Sahgal, V., Yue, G.H., 2004. From mental power to muscle power--gaining strength by using the mind. Neuropsychologia 42, 944-956. https://doi.org/10.1016/j.neuropsychologia.2003.11.018

Richter, M., Gendolla, G.H.E., Wright, R.A., 2016. Chapter Five - Three Decades of Research on Motivational Intensity Theory: What We Have Learned About Effort and What We Still Don't Know, in: Elliot, A.J.B.T.-A. in M.S. (Ed.). Elsevier, pp. 149-186. https://doi.org/https://doi.org/10.1016/bs.adms.2016.02.001

Rozand, V., Lebon, F., Papaxanthis, C., Lepers, R., 2015. Effect of mental fatigue on speed$\begin{array}{lllll}\text { accuracy } & \text { trade-off. } & \text { Neuroscience } & 297,\end{array}$ https://doi.org/10.1016/j.neuroscience.2015.03.066

Rozand, V., Lebon, F., Papaxanthis, C., Lepers, R., 2014. Does a mental training session induce neuromuscular fatigue? Med. Sci. Sport. Exerc. 46, 1981-1989. https://doi.org/10.1249/MSS.0000000000000327

Rozand, V., Lebon, F., Stapley, P.J., Papaxanthis, C., Lepers, R., 2016. A prolonged motor imagery session alter imagined and actual movement durations: Potential implications for neurorehabilitation. Behav. Brain Res. 297, 67-75. https://doi.org/10.1016/j.bbr.2015.09.036

Ruffino, C., Gaveau, J., Papaxanthis, C., Lebon, F., 2019. An acute session of motor imagery training induces use-dependent plasticity. Sci. Rep. 9, 20002. https://doi.org/10.1038/s41598$019-56628-\mathrm{z}$

Ruffino, C., Papaxanthis, C., Lebon, F., 2017. Neural plasticity during motor learning with motor imagery practice: Review and perspectives. Neuroscience 341, 61-78. https://doi.org/10.1016/j.neuroscience.2016.11.023

Saimpont, A., Malouin, F., Tousignant, B., Jackson, P.L., 2012. The influence of body configuration on motor imagery of walking in younger and older adults. Neuroscience 222, 49-57. https://doi.org/https://doi.org/10.1016/j.neuroscience.2012.06.066

Schuster, C., Hilfiker, R., Amft, O., Scheidhauer, A., Andrews, B., Butler, J., Kischka, U., Ettlin, T., 2011. Best practice for motor imagery: a systematic literature review on motor imagery training elements in five different disciplines. BMC Med. 9, 75. https://doi.org/10.1186/17417015-9-75

Seed, J.D., St Peters, B., Power, G.A., Millar, P.J., 2019. Cardiovascular responses during isometric exercise following lengthening and shortening contractions. J. Appl. Physiol. 126, 278-285. https://doi.org/10.1152/japplphysiol.00601.2018

Shen, J., Barbera, J., Shapiro, C.M., 2006. Distinguishing sleepiness and fatigue: focus on definition and measurement. Sleep Med. Rev. 10, 63-76. 
https://doi.org/10.1016/j.smrv.2005.05.004

Shou, G., Ding, L., 2013. Ongoing EEG oscillatory dynamics suggesting evolution of mental fatigue in a color-word matching stroop task, in: 2013 6th International IEEE/EMBS Conference on Neural Engineering (NER). IEEE, San Diego, CA, USA, pp. 1339-1342. https://doi.org/10.1109/NER.2013.6696189

Siemionow, V., Yue, G.H., Ranganathan, V.K., Liu, J.Z., Sahgal, V., 2000. Relationship between motor activity-related cortical potential and voluntary muscle activation. Exp. Brain Res. 133, 303-311. https://doi.org/10.1007/s002210000382

Smirmaul, B.P.C., 2014. Feedback from group III/IV muscle afferents is not the sensory signal for perception of effort. Exp. Physiol. https://doi.org/10.1113/expphysiol.2014.078816

Smith, M.R., Chai, R., Nguyen, H.T., Marcora, S.M., Coutts, A.J., 2019. Comparing the effects of three cognitive tasks on indicators of mental fatigue. J. Psychol. 153, 759-783. https://doi.org/10.1080/00223980.2019.1611530

Smith, M.R., Coutts, A.J., Merlini, M., Deprez, D., Lenoir, M., Marcora, S.M., 2016a. Mental fatigue impairs soccer-specific physical and technical performance. Med. Sci. Sport. Exerc. 48, 267-276. https://doi.org/10.1249/MSS.0000000000000762

Smith, M.R., Marcora, S.M., Coutts, A.J., 2015. Mental fatigue impairs intermittent running performance. Med. Sci. Sports Exerc. 47, 1682-1690. https://doi.org/10.1249/MSS.0000000000000592

Smith, M.R., Zeuwts, L., Lenoir, M., Hens, N., De Jong, L.M.S., Coutts, A.J., 2016b. Mental fatigue impairs soccer-specific decision-making skill. J. Sports Sci. 34, 1297-1304. https://doi.org/10.1080/02640414.2016.1156241

Solodkin, A., Hlustik, P., Chen, E.E., Small, S.L., 2004. Fine modulation in network activation during motor execution and motor imagery. Cereb. Cortex 14, 1246-1255. https://doi.org $10.1093 /$ cercor/bhh086

Steele, J., Fisher, J., 2018. Effort, Discomfort, Group III/IV Afferents, Bioenergetics, and Motor Unit Recruitment. Med. Sci. Sports Exerc. https://doi.org/10.1249/MSS.0000000000001605

Stinear, C.M., Byblow, W.D., Steyvers, M., Levin, O., Swinnen, S.P., 2006. Kinesthetic, but not visual, motor imagery modulates corticomotor excitability. Exp. brain Res. 168, 157-64. https://doi.org/10.1007/s00221-005-0078-y

Taylor, J.L., Amann, M., Duchateau, J., Meeusen, R., Rice, C.L., 2016. Neural Contributions to Muscle Fatigue: From the Brain to the Muscle and Back Again. Med. Sci. Sport. Exerc. 48. https://doi.org/10.1249/MSS.0000000000000923

Thoroughman, K.A., Shadmehr, R., 1999. Electromyographic correlates of learning an internal model of reaching movements. J. Neurosci. 19, 8573-8588. https://doi.org/10.1523/JNEUROSCI.19-19-08573.1999

Tran, Y., Craig, A., Craig, R., Chai, R., Nguyen, H., 2020. The influence of mental fatigue on brain activity: Evidence from a systematic review with meta-analyses. Psychophysiology 57, 1-17. https://doi.org/10.1111/psyp.13554 
van der Linden, D., Frese, M., Meijman, T.F., 2003. Mental fatigue and the control of cognitive processes: effects on perseveration and planning. Acta Psychol. (Amst). 113, 45-65. https://doi.org/10.1016/S0001-6918(02)00150-6

Wascher, E., Rasch, B., Sänger, J., Hoffmann, S., Schneider, D., Rinkenauer, G., Heuer, H., Gutberlet, I., 2014. Frontal theta activity reflects distinct aspects of mental fatigue. Biol. Psychol. 96, 57-65. https://doi.org/10.1016/j.biopsycho.2013.11.010

Yue, G., Cole, K.J., 1992. Strength increases from the motor program: comparison of training with maximal voluntary and imagined muscle contractions. J. Neurophysiol. 67, 1114-1123. https://doi.org/10.1152/jn.1992.67.5.1114 